\title{
REGLAS Y PRINCIPIOS DE JUSTICIA TRIBUTARIA: APORTES DEL DERECHO ESPAÑOL AL DERECHO COMPARADO*
}

\section{PATRICIO MASBERnAT**}

RESUMEN: A fin de verificar las posibilidades de construir una dogmática jurídica relativa a los principios tributarios de carácter material o de justicia tributaria en Chile, considerando el Derecho Comparado, en este artículo se analiza el desarrollo de los mismos en el Derecho español, en el contexto del deber constitucional a contribuir a los gastos públicos. Se revisa dicha categoría, como asimismo los principios de generalidad, igualdad, progresividad, no confiscatoriedad y capacidad económica. Todos ellos se comprenden en el principio de justicia tributaria. La concreción de este último exige el desarrollo dogmático de todos los principios materiales de la tributación, en conjunto y no solo individualmente, dada la profunda interrelación existente entre ellos. No obstante ello, hay algunos especialistas que defienden la existencia de un principio de justicia tributaria autónomo. El artículo enfatiza las complejidades a considerar que se presentan dentro del análisis de cada principio mencionado, y que, en definitiva, se traspasan al objetivo constitucional de crear un sistema tributario justo.

PALABRAS CLAVE: Principios tributarios materiales - Principios de justicia tributaria; igualdad tributaria; capacidad contributiva; progresividad.

Fecha de recepción: 27 de septiembre de 2012.

Fecha de aprobación: 16 de enero de 2013.

** Licenciado en Derecho por la Pontificia Universidad Católica de Chile, Magíster en Derecho por la Universidad de Chile, Doctor en Derecho (Instituto Universitario de Derecho Comparado, Facultad de Derecho) Universidad Complutense de Madrid. Profesor de Derecho tributario, Universidad Autónoma (Chile). Correo electrónico: pmasbernat@alburquenque.cl. El presente trabajo se enmarca en el Proyecto FONDECYT Código 11100190 , "Construcción de una dogmática de los principios materiales de la tributación en Chile, a la luz del Derecho Comparado" ( $2^{\circ}$ año), del que el Dr. Masbernat es investigador responsable. Asimismo, se enmarca en los siguientes Proyectos CONICYT de Atracción de Capital Humano Avanzado de Extranjero, MEC, de los que el Dr. Masbernat ha oficiado como investigador ejecutor responsable, Folios CONICYT No 80112004/2012 y No 80112003/2012. Agradezco los comentarios del Dr. José Antonio Fernández Amor (Universidad Autónoma de Barcelona), por los comentarios a una primera versión del presente trabajo. Los errores que quedaren son de mi responsabilidad. También agradezco al Catedrático Dr. Antonio Cayo, de la Universidad Complutense de Madrid, lugar donde terminó de redactarse este artículo en una estadía de investigación, donde el catedrático ofició de anfitrión. 


\section{RULES AND PRINCIPLES OF TAX JUSTICE: CONTRIBUTIONS of SPAIN TO COMPARATIVE LAW}

ABSTRACT: In order to verify the possibilities of building a legal doctrine about the material tax principles or tax justice principles in the Chilean Legal System, considering Comparative Law, this paper analyzes the development of the same in the Spanish Legal System, in the context of constitutional duty to contribute to public expenses. The category is reviewed as well as the principles of generality, equality, progressiveness, non-confiscation and economic capacity to pay. They are enclosed in the principle of tax fairness. The concretion of the latter requires the dogmatic development of all the material principles of taxation, as a whole and not individually, given the deep interrelation between them. Nevertheless, there are some experts who defend the existence of an autonomous principle of tax justice. The article emphasizes the complexities to consider in the analysis presented of every principle mentioned, and definitely they are transferred to the constitutional goal to create a fair tax system.

KEY WORDS: Material tax principles - Principles of tax justice - tax equity - ability to pay - progressivity.

Sumario: 1) Introducción. 2) La justicia tributaria como fundamento del deber constitucional de contribuir a los gastos públicos. 3) Los principios tributarios materiales. 4) Conclusiones. 5) Bibliografía

\section{1) INTRODUCCIÓN}

En el contexto del Derecho chileno, la doctrina no se ha ocupado de estudiar los principios tributarios materiales y, por el contrario, ha enfatizado los análisis de los principios de carácter propiamente formal (reserva de ley bajo la denominación de principio de legalidad ${ }^{1}$, irretroactividad de las sanciones, seguridad jurídica, etc. ${ }^{2}$ ), del principio de igualdad ante

El principio de legalidad no es el único principio formal acuerdo al Derecho Comparado. En España, otros son visualizados (por clara expresión en el artículo 9.3 C.Pol.Esp), tales como el de seguridad jurídica [Romero García, Felipe (2005) El valor sistema tributario: acerca de su integración entre los principios de la imposición. Cádiz: Servicio de Publicaciones de la Universidad de Cádiz, pp. 313 ss.; Gascó Casesnoves, María (1993). "Principios constitucionales y su aplicación al Derecho tributario”. Revista Palau, 14, p. 19], tipicidad o irretroactividad.

2 Albiñana García-Quintana, César (1992) Sistema tributario español y comparado. Madrid: Tecnos, p. 65; Falcón y Tella, Ramón (1996). "Retroactividad de las normas tributarias y devengo del impuesto". Quincena Fiscal Aranzadi, 21 [disponible en base de datos Westlaw 
la ley (también en un sentido formal, como idea expresiva de la no discriminación arbitraria y en gran medida análoga al principio de generalidad), y de los derechos de propiedad y libre empresa como límites de la potestad tributaria (bajo la idea de no confiscatoriedad y prohibición de tributos manifiestamente desproporcionados e injustos) ${ }^{3}$.

No obstante la escasa atención de los autores, la jurisprudencia del Tribunal Constitucional chileno da cuenta de que los abogados defienden cada vez más causas sobre la base de los principios materiales de la tributación, instando a un debate sobre ellos en el foro. Los resultados aparecen como insuficientes, probablemente a causa del citado déficit dogmático. De ahí que es posible sostener que, salvo algunos matices de diferenciación, la jurisprudencia constitucional ha seguido el mismo derrotero que la doctrina ${ }^{4}$.

En contextos similares, ha sido enfatizada la importancia de estos asuntos. Por dicha razón, en una oportunidad el profesor Klaus TYPKE sostuvo que “[y]a no se sigue el principio: ¡La ley es la ley! Sino que el legislador está sometido a los derechos fundamentales. De ahí que el Derecho Tributario tampoco pueda tener cualquier contenido. La principal tarea del Estado de Derecho material es la realización de la justicia material, respetando también, desde luego, los principios formales del Estado de Derecho. [...] La limitación al Estado de Derecho formal puede haber sido todavía aceptable considerando la moderación de la carga tributaria en el siglo XIX; en la situación actual, sin embargo, ya no lo es: actualmente nos encontramos con cargas individuales que hubieren sido inimaginables hace cien años" 5 .

Dado este escenario en el Derecho chileno, y a objeto avanzar en la construcción de una dogmática propia, resulta necesario poner pie en el Derecho Comparado 6 . Dentro del programa de investigación de que

Aranzadi, doc. BIB 1996\1312, fecha de visita septiembre de 2011]; RodríGuez, Álvaro (1998). "Los principios de la imposición en la jurisprudencia constitucional española". Civitas, Revista Española de Derecho Financiero, 100, p. 607.

3 En su construcción doctrinaria, los autores proceden a través de un modelo de interpretación literal y genético (basado en las Actas de la Comisión de Estudios de la Nueva Constitución) del art. 19 No $20 \mathrm{CPCh}$. Para algunos puede resultar la única vía posible, postulado del cual difiero. Un estudio extenso sobre el problema, puede verse en Masbernat, Patricio (2012). "Un análisis crítico de la doctrina relativa a los principios materiales de la tributación en Chile". En AAVV, Problemas Actuales de Derecho Tributario comparado. Una perspectiva de Iberoamérica. Santiago de Chile: Librotecnia, pp. 433-474.

$4 \quad$ Masbernat, Patricio (2012). "El desarrollo de los principios constitucionales tributarios de carácter material en la jurisprudencia del Tribunal Constitucional". Revista de Derecho, Universidad Católica del Norte, 19 № 1, en prensa.

5 Tipke, Klaus (1990) Principios constitucionales en el derecho tributario alemán, Seminario Hispano Alemán de Derecho Tributario. Madrid: IEF, Edición sin encuadernar, p. 1.

6 Se ha intentado probar la posibilidad jurídica del encaje de dichos principios en el ordenamiento chileno, estimo que con éxito, en un trabajo colectivo recientemente enviado a publicación, denominado, "Los principios materiales de la tributación en los ordenamientos 
forma parte este trabajo, uno de los puntos de referencia es el Derecho español. En este artículo se comunicarán los elementos básicos, en honor al espacio disponible, del desarrollo de los principios de justicia tributaria en dicho ordenamiento jurídico.

Para los fines indicados, se contextualizarán los indicados principios materiales en el marco del deber constitucional de contribuir a los gastos públicos, teniendo presente que el objetivo constitucional es la construcción de un sistema tributario justo. Luego se describirán correlativamente cada uno de los principios a efectos de observar la conformación y delimitación de cada uno de ellos, informando a su vez del modo que, en conjunto operan a efectos de lograr su fin de justicia.

\section{2) LA JUSTICIA TRIBUTARIA COMO FUNDAMENTO DEL DEBER CONSTI- TUCIONAL DE CONTRIBUIR A LOS GASTOS PÚBLICOS}

La norma constitucional esencial de esta materia, aunque no la única, está constituida por el artículo 31.1 de la Constitución espańola (en adelante, C.Pol.Esp.): “Todos contribuirán al sostenimiento de los gastos públicos de acuerdo con su capacidad económica mediante un sistema tributario justo inspirado en los principios de igualdad y progresividad que, en ningún caso, tendrá alcance confiscatorio". Estos principios son reconocidos también en el art. 3.1. de la Ley General Tributaria (58/2003, en adelante LGT), aunque de una perspectiva técnica algo distinta, en concreto, como principios de aplicación ${ }^{7}$, esto es, suponen mandatos a los cuales debe sujetarse la Administración en el ejercicio de sus potestades y en sus relaciones con los contribuyentes ellos.

Los principios materiales de la tributación se encuentran incorporados en la disposición constitucional citada y son los siguientes: capacidad económica; igualdad; generalidad; progresividad; no confiscatoriedad (prohibición de que el sistema tributario tenga alcance confiscatorio) ${ }^{8}$.

de Italia, España y Argentina. Perspectiva para la construcción de una dogmática en Chile”, escrito por profesores de varios países (Cristian Billardi, Jose A. Fernández, Miguel A. Sánchez, y P. Masbernat).

$7 \quad$ Artículo 3 de la LGT. "Principios de la ordenación y aplicación del sistema tributario.1. La ordenación del sistema tributario se basa en la capacidad económica de las personas obligadas a satisfacer los tributos y en los principios de justicia, generalidad, igualdad, progresividad, equitativa distribución de la carga tributaria y no confiscatoriedad. 2. La aplicación del sistema tributario se basará en los principios de proporcionalidad, eficacia y limitación de costes indirectos derivados del cumplimiento de obligaciones formales y asegurará el respeto de los derechos y garantías de los obligados tributarios".

8 Medina (2010). "Las obligaciones tributarias". Derecho Constitucional III [base de datos Iustel (RI \$910504), visitada en septiembre de 2011]. 
Existe consenso acerca de que todos estos principios constitucionales tributarios específicos conforman un bloque, se encuentran interrelacionados ${ }^{9}$, y se condicionan mutuamente (lo que ha sido recordado por el TCE $)^{10}$, y en conjunto configuran el principio de justicia tributaria, siendo la base sobre el que se sustenta el deber constitucional de contribuir a los gastos públicos.

Cabe destacar que los principios constitucionales específicamente tributarios concurren, tanto en abstracto como en cada caso concreto, junto a los muchos otros principios y derechos constitucionales ${ }^{11}$, y, en tal sentido, se ha resuelto por el TCE en diversas oportunidades ${ }^{12}$. Ello se debe a que, de acuerdo al artículo 31.1 C.Pol.Esp., los principios tributarios se encuentran entrelazados bajo la idea de "sistema tributario justo" 13 y, en cuanto normas constitucionales, pertenecen a su vez al sistema constitucional.

En efecto, desde una perspectiva sistemática, esta materia es posible conectarla con otras normas constitucionales, entre ellas, las que establecen los principios rectores de la política económica y social (artículos 39 a 52 C.Pol.Esp. $)^{14}$. De modo más amplio, también se enmarca en la cláusula del Estado Social y Democrático de Derecho (que establece un valor constitucional al cual se sujetan los principios) "con cuya declaración el Estado asume una función social de redistribución de la renta y de la riqueza y cuyas consecuencias se reflejan en el sistema tributario"15, siendo

9 En España se ha reiterado la aseveración acerca de los fuertes lazos entre los principios de justicia tributaria. Por ejemplo, la STCE 46/2000, de 17 de febrero, sostuvo que: "La igualdad ante la Ley resulta, pues, indisociable de los principios de capacidad económica, así como de los de generalidad, justicia y progresividad, que se enuncian en el último precepto constitucional citado (STCE 27/1981, de 20 de julio, FJ 4; STCE 19/1987, de 17 de febrero, FJ 3; STCE 209/1988, de 10 de noviembre, FJ 6; 45/1989, de 20 de febrero, FJ 4; STCE 54/1993, de 15 de febrero, FJ 1; STCE 134/1996, de 22 de julio, FJ 5)".

10 Pauner (2001)146.

11 Collado Yurrita, Miguel Ángel y Moreno González, Saturnina (2007). “Tema 2: Principios constitucionales del Derecho Tributario”. En Collado Yurrita, Miguel Ángel (director) y Luchena Mozo, Gracia María (coordinador): Derecho Tributario, Parte General. 2a edición. Madrid: Editorial Atelier, p. 37.

12 Lo destacan diversos autores. Gallego Peragón, José Manuel (2003) Los principios materiales de justicia tributaria. Granada: Comares, p. 70.

13 Herrera Molina, Pedro Manuel (1996). "Una decisión audaz del Tribunal Constitucional alemán: el conjunto de la carga tributaria del contribuyente no puede superar el 50 por 100 de sus ingresos". Impuestos, 14, p. 1039. Extenso en Romero García, Felipe (2005) El valor sistema tributario: acerca de su integración entre los principios de la imposición. Cádiz: Servicio de Publicaciones de la Universidad de Cádiz.

14 Prada Fernández de Sanmamed, José Luis (2009). "Los principios rectores de la política social y económica”. Derecho Constitucional III. [base de datos Iustel, visitada en septiembre de 2011].

15 PAuner (2001) 144 
el artículo 31.1. C.Pol.Esp. los que especifican los principios básicos y fundamentales sobre los que se basa el sistema tributario ${ }^{16}$.

El deber de contribuir al sostenimiento de los gastos públicos presenta múltiples fundamentos, entre ellos, el principio de solidaridad ${ }^{17}$ social y económica y la función social de la propiedad. Esta obligación se configura conforme a ciertos principios e involucra derechos de rango constitucional, por lo que debe sujetarse a una dogmática de los derechos fundamentales. Por ello, al exigir el cumplimiento de este deber, el Estado no puede vulnerar esos derechos, ya que se configura (y existe) de acuerdo a los mismos y, en todo caso (v.g., en caso de conflictos de intereses), debe ser objeto de ponderación con los bienes constitucionalmente reconocidos implicados. De este modo, los derechos fundamentales podrían sujetarse a matizaciones o limitaciones a fin de que este deber se materialice. Con esto, se pone de manifiesto que el poder tributario se basa en un deber fundamental de contribuir a los gastos públicos exigible a los ciudadanos, originado en la exigencia de cubrir las necesidades públicas y de cumplimiento de los fines sociales que el Estado debe perseguir para satisfacer otros derechos individuales (v.g., derechos de defensa judicial de los pobres) y los derechos sociales de carácter fundamental.

El principio de justicia tributaria, expresado en la norma constitucional citada, fija como objetivo normativo la construcción de un "sistema tributario justo, inspirado en los principios de igualdad y progresividad que, en ningún caso, tendrá alcance confiscatorio", sujeto a la obligación

Pauner (2001) 142.

La palabra "solidaridad" viene de la expresión romana in solidum, referido a la situación en la cual diversas personas se comprometen a pagar el todo de una deuda común, y que entra al constitucionalismo mediante el principio de fraternidad del proceso revolucionario francés [Bilbeny, Norbert (1991). "Igualdad y principio de solidaridad". El principio de igualdad en la Constitución Española: XI Jornadas de Estudio. Madrid: Ministerio de Justicia, Centro de Publicaciones, I, p. 53.] El principio de solidaridad forma parte consustancial del Estado social de Derecho [López Guerra, Luis y otros (2007) Derecho constitucional I: El ordenamiento constitucional. Derechos y deberes de los ciudadanos. Valencia: Tirant lo Blach, p. 449; Álavarez Conde, Enrique (2008) Derecho constitucional. Madrid: Tecnos, I, p. 106 ss.] y, a nivel normativo constitucional, encuentra consagración en diversas disposiciones básicamente referido a la solidaridad interterritorial (artículos 2, 9.2, 138.1, 156.1, 158.2 C.Pol.Esp.; y en el capítulo $3^{\circ}$ del título $1^{\circ}$ de la misma, rubricado: De los principios rectores de la política social y económica", aunque también se encuentra explícita o implícitamente incorporado en otras disposiciones (artículo 45 C.Pol.Esp.). También cabe relacionarlo al principio relativo al progreso social (artículo 40.1), por el que se obliga a los poderes públicos a promover una distribución más equitativa de la renta [ÁLVAREZ (2008) 630]. Su importancia ha sido reconocida por el Tribunal Constitucional español, en la sentencia No $110 / 1984$, donde ha resuelto que este principio constituye uno de los fundamentos del deber de contribuir y de las bases de un sistema tributario justo. Aún más, en sentencia No 182/1997, fundamento jurídico $6^{\circ}$ ha denominado al tributo como "contribución de solidaridad". Herrera (1998) 93, destaca que para la doctrina comparada, la solidaridad es el fundamento del sistema financiero y del tributo). 
de que "todos" contribuyan al sostenimiento de los gastos públicos de acuerdo con su respectiva capacidad económica ${ }^{18}$.

Este imperativo de justicia tributaria, como carácter definitorio del sistema tributario, por algunos ha sido entendido como un principio autónomo; y por otros, como una consecuencia de la concurrencia o cumplimiento de aquellos claramente exigidos en el artículo 31.1 constitucional ${ }^{19}$.

Ninguna de ambas tesis se encuentra libre de refutaciones.

En efecto, de sostenerse la segunda teoría, la declaración constitucional aparecería vacía de contenido.

Al contrario, defender la primera opción genera dos clases de problemas: la dificultad de determinar qué añade concretamente la justicia tributaria y, además, la de agregar mayores restricciones al legislador en la configuración del sistema fiscal las que, con todo, no deben llegar a neutralizar su libertad de conformación política.

Frente a estas dificultades, el TCE ha rehuido delimitar este concepto, aunque en sus declaraciones ha vertido, de modo parcial, muchos elementos a tener en cuenta ${ }^{20}$.

De este modo, el TCE ha sostenido que el principio de capacidad contributiva no agota el contenido constitucional de la justicia tributaria, que el sistema justo que se proclama no puede separarse en ningún caso del principio de progresividad ni del principio de igualdad, y exige la observancia de la totalidad de los principios explícitamente recogidos en el artículo 31.1 C.Pol.Esp (STCE 27/1981, FJ 40; STCE 221/1992, FJ 4º ${ }^{21}$.

En pronunciamientos posteriores, el TCE ha vinculado la justicia tributaria al cumplimiento de uno o más principios del artículo 31.1 C.Pol. Esp, especialmente con el de igualdad. Sin embargo, ocasionalmente el

\footnotetext{
18 Medina (2010).

19 Como lo cree Medina (2010). También Eseverri Martínez [Eseverri Martínez, Ernesto (2006) Derecho Tributario: Parte General. Valencia: Tirant lo Blanch, p. 26], para quien la justicia tributaria se sustenta sobre la base de las condicionantes de justicia material contenidas en el deber de contribuir expresamente indicadas en el artículo 31.1 C.Pol.Esp. Otros matizan, como Calvo Ortega, para quien la justicia tributaria puede considerarse como un principio general que engloba todo el sistema y que incluiría la generalidad, la capacidad económica y la progresividad, pero no la prohibición de confiscatoriedad.

20 Medina (2010)

21 STCE 27/1981, FJ 40: "Aunque una definición válida de lo que debe entenderse por justo, a efectos tributarios, seria una tarea que rebasa el planteamiento que aqui hemos de hacernos, lo que no puede soslayarse es que el legislador constituyente ha dejado bien claro que el sistema justo que se proclama no puede separarse, en ningún caso, del principio de progresividad ni del principio de igualdad. Es por ello-porque la igualdad que aqui se reclama va intimamente enlazada al concepto de capacidad económica y al principio de progresividad- por lo que no puede ser, a estos efectos, simplemente reconducida a los términos del artículo 14 de la Constitución: una cierta desigualdad cualitativa es indispensable para entender cumplido este principio. Precisamente la que se realiza mediante la progresividad global del sistema tributario en que alienta la aspiración a la redistribución de la renta".
} 
TCE sugiere que el principio de justicia tributaria tiene una existencia propia e independiente ${ }^{22}$.

En alguna ocasión, incluso, ha considerado que su vulneración constituye directamente una causa de inconstitucionalidad, como en la STCE $221 / 1992$, en un caso en que el legislador no consideró el factor inflación, con lo que se podría llegar a gravar rentas no reales y con ello lesionar el mandato constitucional de establecer un sistema tributario justo ${ }^{23}$.

Muy recientemente, el profesor Calvo OrTEga ha entregado nuevos argumentos en defensa de la tesis de la existencia de un principio autónomo de justicia tributaria, con un carácter complementario de los principios específicos de la tributación ${ }^{24}$. Sustenta que es necesario dar lugar a este principio general, debido a que en sus esferas específicas de aplicación, muchas veces los principios específicos no entregan soluciones a muchos casos concretos ${ }^{25}$. En efecto, añade, el principio de justicia tributaria puede iluminar al resto de principios específicos (que son abstractos

22 Medina (2010). Este autor lo deduce de STCE 173/1996 (FJ 50 c): "[...] la observancia del principio de igualdad es pieza esencial de todo sistema tributario justo", aunque "la realización de dichos principios de justicia e igualdad en el ámbito tributario debe armonizarse con el respeto de los principios informadores del ordenamiento juridico $y$, de manera especial, con la seguridad juridica".

23 STCE 221/1992, FJ 50: "No puede desconocerse, sin embargo, que el mantenimiento a ultran$z a$, sin excepciones, del principio nominalista en el ordenamiento tributario puede dar lugar, en ciertos casos, a situaciones incompatibles con la plena vigencia del sistema tributario justo a que se refiere el articulo 31.1 del Texto Constitucional. Los citados efectos se evidencian en periodos de inflación especialmente aguda en el seno de aquellas figuras del sistema tributario que más directamente pueden verse afectados por las elevaciones del nivel general de precios. En tales casos, la valoración de los elementos patrimoniales según criterios estrictamente nominales puede conducir a gravar en todo o en parte rentas aparentes, no reales. Por ello, este Tribunal ha señalado, a propósito del Impuesto sobre la Renta, que responde a la naturaleza de dicho impuesto, que ha de contemplar incrementos reales no monetarios, su adecuación a la situación inflacionista" (STCE 27/1981, FJ 60). Por otra parte, el TCE ha puesto de relieve el papel del IRPF en la configuración del sistema tributario justo que reclama la C.Pol.Esp (STCE 46/2000, FJ $6^{\circ}$ ), por considerar que es a través de este Impuesto como se realiza la personalización del reparto de la carga fiscal en el sistema tributario según los criterios de capacidad económica, igualdad y progresividad.

24 Calvo Ortega, Rafael (2012) ¿Hay un principio de justicia tributaria? Pamplona: Cuadernos Civitas, Thomson Reuter/Editorial Aranzadi, 127 pp.

25 En el Capítulo XIII de su libro, el Profesor Calvo hace referencia a la Ley General Tributaria, que en su artículo $3^{\circ}$ menciona principios de ordenación del sistema tributario: capacidad económica, justicia, generalidad, igualdad, progresividad, equitativa distribución de la carga tributaria, y no confiscatoriedad; y también alude a los principios de aplicación del sistema: proporcionalidad, eficacia, limitaciones de costes indirectos al contribuyente derivado de obligaciones formales, respeto de los derechos y garantías de los obligados tributarios. La importancia que este autor observa en este cuerpo legal, es que permite la invocación individual (porque lo reconoce autónomamente) del principio de justicia tributaria, sin necesaria relación a los demás principios específicos. La conclusión a que se llegaría es que, sin un caso concreto se resuelve de modo directo con la aplicación de un principio específico, no es necesario acudir al principio de justicia tributaria. Por el contrario, será necesario recurrir a él en caso de que una situación no quede cubierta por un principio específico. Calvo (2012) 113 y ss. 
y graduables) para resolver problemas concretos (ajustándolos y modulándolos), o en definitiva hacerlo en caso de que los otros no operen. Si lo interpreto correctamente, el principio en estudio constituiría un elemento de cierre que permite al ordenamiento construir un sistema tributario de acuerdo al ideal de justicia.

En cuanto al contenido, Calvo Ortega sostiene que la justicia tributaria no se agota en los principios materiales (referidos a la distribución de la carga tributaria), pues envuelve también a los principios de reserva de ley y certeza jurídica (que son principios formales). Además de los anteriores, involucra al respeto de los principios legales o de aplicación; a los derechos y garantías de los obligados tributarios; a los deberes de objetividad y eficiencia de los poderes públicos; la proporcionalidad y racionalidad de las normas y decisiones administrativas; la interdicción de la responsabilidad objetiva de los obligados tributarios; la obligación de devolución de ingresos indebidos; la reserva de los datos privados; el adecuado funcionamiento de los servicios fiscales; el costo mínimo para el contribuyente; entre otros variados asuntos.

\section{3) LOS PRINCIPIOS TRIBUTARIOS MATERIALES}

A) El principio de generalidad encuentra su base normativa en la expresión "todos" del artículo 31.1 C.Pol.Esp. ${ }^{26}$, e implica que "todos tienen el deber de contribuir al mantenimiento de los gastos públicos".

Este principio cubre subjetivamente a todas las personas con capacidad económica suficiente, y objetivamente a todas las situaciones reveladoras de riqueza suficiente, y, al contrario, solo se excluirá a aquellos que carezcan de capacidad económica ${ }^{27}$.

Se erige como una consecuencia del precepto de la igualdad, e implica que el tributo se aplique sin realizar discriminaciones o excepciones no objetivamente justificadas en criterios de justicia ${ }^{28}$ y que cuenten con características de abstracción e impersonalidad, y por ello, constituye un

26 Conforme lo ha puesto de manifiesto el STCE 96/2002, FJ 70: “La expresión "todos” absorbe el deber de cualesquiera personas, fisicas o juridicas, nacionales o extranjeras, residentes o no residentes, que por sus relaciones económicas con o desde nuestro territorio (principio de territorialidad) exteriorizan manifestaciones de capacidad económica, lo que les convierte también, en principio, en titulares de la obligación de contribuir conforme al sistema tributario".

27 Escribano López, Francisco (1991). "Principio de igualdad y deber de contribuir en la jurisprudencia constitucional”. El principio de igualdad en la Constitución española: XI Jornadas de Estudio. Madrid: Ministerio de Justicia, Centro de Publicaciones, I, pp. 713-776.

28 Una diferenciación basada en criterio de justicia es aquella dispuesta conforme a la capacidades económica de los contribuyentes y que cuando no existe o sea mínima, el contribuyente sea liberado del deber de contribuir; o se resuelva del mismo modo los casos en que una misma realidad económica resulte gravada por dos figuras tributarias diferentes. ESEVERri (2006) 34 y 35. 
mandato al legislador para que no dicte leyes que establezcan situaciones de privilegios innecesarios, gratuitos, arbitrarios, ausentes de justificación ${ }^{29}$.

Desde esta perspectiva objetiva, la exigencia de generalidad obliga al legislador a "tipificar como hecho imponible todo hecho, acto o negocio jurídico que sea indicativo de capacidad económica" 30 . En razón de lo afirmado, se encuentra enraizado en los principios de igualdad y capacidad económica ${ }^{31}$, y de este modo, exige que todos sean llamados a contribuir, a soportar los gastos públicos, aunque finalmente no todos deban de modo efectivo pagar, ya que ello dependerá del juego del resto de los principios constitucionales tributarios y de las leyes que los desarrollan ${ }^{32}$.

Desde una perspectiva subjetiva, este principio prohíbe la existencia de privilegios fiscales de cualquier género en la medida que no se justifiquen en principios del mismo nivel de importancia y frente a situaciones válidas para sostenerlos, v.g., la protección de la familia, y, en general, los principios rectores de la política social y económica establecidos en la Constitución. Esto nos conduce a materias tales como las funciones o fines extrafiscales de los tributos, cuestión que ha sido reconocida por el TCE, v.g., en la sentencia No 37/1987, de 28 de marzo. Por tanto, el principio de generalidad se encuentra encadenado al elemento subjetivo de la obligación tributaria, al sujeto llamado a contribuir, puesto que, si bien afecta a todos los miembros de la comunidad, ello sucede en conexión a los principios de igualdad y capacidad económica ${ }^{33}$.

Por lo hasta aquí expuesto, la generalidad no se opone a la existencia de exenciones de ciertos tributos o bonificaciones con relación a grupos homogéneos de personas, y solo impide su alcance a personas determinadas. Con todo, la libertad del legislador se encuentra limitada ${ }^{34}$ para establecer esos supuestos excepcionales, por cuanto dichas medidas deben vincularse a la satisfacción de algún interés general constitucionalmente protegido o al cumplimiento del principio de capacidad contributiva ${ }^{35}$.

29 ESEVERRI (2006) 34.

30 Fernández Segado, Francisco (1997). "El diseño constitucional del deber de contribuir al sostenimiento de los gastos públicos". Revista Vasca de Administración Pública. Herri-Arduralaritzako Euskal Aldizkaria, No 47, 1, p. 90.

31 Gallego (2003) 203.

32 Fernández (1997) 90.

33 Gallego (2003) 203.

34 Limitada, en el sentido de circunscrita o restringida, es decir, posible solo bajo determinadas condiciones. Nótese cómo se tornan relevantes los mecanismos tales como el de ponderación o el control de proporcionalidad.

35 Como lo seńala el fundamento jurídico $6^{\circ}$ de la sentencia del TCE 134/1996, aunque posteriores declaraciones del TCE - como la sentencia 96/2002- han matizado dicha línea jurisprudencial en el sentido de no exigir necesariamente rango constitucional a los fines de interés general cuyo cumplimiento puede justificar el establecimiento de tales excepciones 
Estos razonamientos fueron expresados por el Tribunal Constitucional en su sentencia No 57/2005, de 14 de marzo, fundamento jurídico 40: "[...] la exención o bonificación-privilegio de su titular-como quiebra del principio de generalidad que rige la materia tributaria, en cuanto que neutraliza la obligación tributaria derivada de la realización de un hecho generador de capacidad económica, solo será constitucionalmente válida cuando responda a fines de interés general que la justifiquen (por ejemplo, por motivos de politica económica o social, para atender el minimo de subsistencia, por razones de técnica tributaria, etc.), quedando en caso contrario, proscrita, pues no hay que olvidar que los principios de igualdad y generalidad se lesionan cuando se utiliza un criterio de reparto de las cargas públicas carentes de cualquier justificación razonable $y$, por tanto, incompatibles con un sistema tributario justo como el que nuestra Constitución consagra en el artículo 31".

B) El principio de igualdad tributaria postula, en una versión muy simplificada, que la ley debe brindar un trato igual a los iguales y desigual a los desiguales, conforme las personas se encuentren en las mismas o en diferentes situaciones ${ }^{36}$.

La C.Pol.Esp. incorpora a la igualdad como un valor (art. 1), como un deber (art. 9.2), como un derecho (arts. 14, 23, 32.1, 139) y, como un

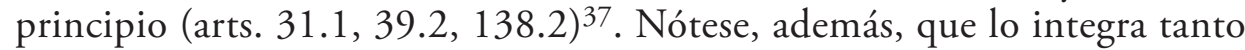
una faceta principio formal como otra material.

Como se ha mostrado, la C.Pol.Esp. la menciona en el art. 31.1, a propósito del deber de contribuir, mediante el cual se ordena al legislador implantar un sistema tributario justo sustentado, entre otras bases, en la igualdad.

También es interesante destacar las expresiones más genéricas del valor y del principio de igualdad que se encuentran en el art. 1.1 (que puede enlazarse con los principios rectores de la política económica y social) y en el art. 14, ambos de la C.Pol.Esp. El primero dice: "España se constituye en un Estado social y democrático de Derecho, que propugna como valores superiores de su ordenamiento jurídico la libertad, la justicia, la igualdad y el pluralismo político". El artículo 14 expresa: "Los españoles son iguales ante la ley, sin que pueda prevalecer discriminación alguna por razón de nacimiento, raza, sexo, religión, opinión o cualquier otra condición o circunstancia personal o social".

Asimismo, la C.Pol.Esp. contempla la promoción de la igualdad material (real y efectiva) entre los individuos y grupos, a través de un mandato dirigido a los órganos estatales y que debe concretarse, entre otras vías,

\footnotetext{
aunque, por cierto, declara la prohibición en la concesión de privilegios tributarios discriminatorios. Medina (2010).

36 ESEVERRI (2006) 30.

37 Gallego (2003) 132.
} 
mediante el sistema tributario, como manifiesta el art. 9.2 constitucional: "Corresponde a los poderes públicos promover las condiciones para que la libertad y la igualdad del individuo y de los grupos en que se integra sean reales y efectivas; remover los obstáculos que impidan o dificulten su plenitud y facilitar la participación de todos los ciudadanos en la vida política, económica, cultural y social".

Estas disposiciones producen consecuencias tanto a nivel de los ingresos públicos como de los gastos fiscales (en su exigencia de reparto equitativo, conforme al art. 31.2 constitucional), e implican un requerimiento dirigido a los órganos públicos de promoción de la igualdad real y efectiva, lo que a su vez encuentra fundamento en el principio de solida$\operatorname{ridad}^{38}$.

El art. 9.3 constitucional hace referencia a la interdicción de la arbitrariedad, principio de indudable cercanía con la igualdad. A juicio de algunos autores, supedita especialmente a las administraciones públicas, pero, igualmente, constituye un mandato dirigido al legislador 39: "3. La Constitución garantiza el principio de legalidad, la jerarquia normativa, la publicidad de las normas, la irretroactividad de las disposiciones sancionadoras no favorables o restrictivas de derechos individuales, la seguridad juridica, la responsabilidad y la interdicción de la arbitrariedad de los poderes públicos".

En virtud de estas normas, se ha sostenido que es posible interpretar el principio de igualdad en dos modos distintos.

En un sentido positivo, que exigiría tratar igual a los que se encuentren en las mismas circunstancias y diferente a los que se encuentren en diversas circunstancias.

En un sentido negativo, se lo ha interpretado como supresión de cualquier discriminación arbitraria, lo que puede conectar con el principio de seguridad jurídica y la interdicción de la arbitrariedad. La arbitrariedad es un concepto difuso, abierto en extremo, vinculado a lo que en cada época se entiende como justo, razonable o conforme a la naturaleza de las cosas, y que en cuanto a tal corre el riesgo de escapar del mundo del Derecho.

Sobre la base de la elaboración dogmática expuesta hasta aquí relata$\mathrm{da}$, se ha sostenido que la igualdad tributaria (art. 31.1 C.Pol.Esp.) no es concebible de modo tan riguroso que impida el establecimiento de tratamientos dispares entre los contribuyentes, como lo ha indicado el TCE, puesto que un sistema tributario justo debe fundarse en criterios tales como la progresividad y la capacidad económica ${ }^{40}$. Con todo, el trata-

FERnÁNdez (1997) 105.

Gallego (2003) 71.

Medina (2010). El TCE ha dicho: "El articulo 31.1 de la Constitución establece el principio de que el sistema tributario ha de ser justo e inspirarse en los principios de igualdad y progresividad. La simple mención conjunta de estos dos principios evidencia que el primero de ellos no 
miento tributario diferenciado debe obedecer a una justificación objetiva y razonable (STCE 134/1996, FJ 8º), al mismo tiempo esta regulación desigual debe vincularse a la satisfacción de un objetivo constitucionalmente legítimo y debe testearse si la misma genera unos efectos que resultan desproporcionados al fin perseguido, pues, de ser así, habría que considerar la norma debatida contraria al principio de igualdad (STCE 214/1994, de 14 de julio, FJ 50) ${ }^{41}$.

Si bien le es reconocido al legislador un amplio margen para configurar el orden jurídico, debe obedecer a ciertos límites ya que constituye un obstáculo infranqueable el que la diferencia de trato fiscal se efectúe en atención a condiciones personales que no constituyan elementos determinantes del correspondiente impuesto, de acuerdo a la posición defendida por el TCE, lo que es posible apreciar en su sentencia 45/1989, de 20 de febrero, FJ 40:

"[...] Pero dejando de lado, por el momento, esta evidencia, lo que interesa poner de relieve ahora, para evitar después reiteraciones fatigosas, es que como la carga tributaria a que cada sujeto ha de hacer frente es función de su capacidad económica, la definición de esta y el método para determinarla han de ser establecidos mediante normas que efectivamente den a todos los sujetos un trato igual y no introduzcan entre ellos diferencias resultantes de su propia condición personal, o de las relaciones que existen entre ellos y otras personas cuando ni aquella condición ni estas relaciones son elementos determinantes del impuesto en cuestión. La igualdad es perfectamente compatible con la progresividad del impuesto y solo exige que el grado de la dicha progresividad se determine en función de la base imponible y no en razón del sujeto."

puede ser entendido en términos tales que impidan al legislador, al establecer el sistema fiscal que estima justo, introducir diferenciaciones entre los contribuyentes, bien sea atendiendo a la cuantía de sus rentas, al origen de estas o cualesquiera otra condición social que considere relevante para atender al fin de la justicia" (ATC 230/1984 FJ 1º).

41 Nótese cómo entra a jugar un papel relevante el juicio de proporcionalidad, en el sentido que se concibe en el Derecho comparado. Véase: BARnEs, J. (1994). "Introducción al principio de proporcionalidad en el Derecho Comparado y Comunitario". Revista de Administración Pública, CECP, 135. 
Esta postura de la jurisprudencia constitucional (presente también en STCE 76/1990, de 29 de abril, FJ 9o; STCE 214/1994, de 14 de julio, FJ $8^{\mathrm{o}^{42}}$ ), se resume en los siguientes postulados ${ }^{43}$ :

a) Las discriminaciones normativas carentes de justificación objetiva y razonable, deben quedar proscritas del ordenamiento jurídico.

b) A iguales supuestos de hechos descritos en la ley deben corresponderles las mismas consecuencias jurídicas.

c) Se deben evitar, en el texto de las normas jurídicas, situaciones desiguales artificiosas y arbitrarias.

d) La discriminación normativa es lícita atendiendo no solo a la finalidad que se persiga con su establecimiento, sino además, considerando las circunstancias jurídicas que de ella derivan, entendidas en clave de proporcionalidad.

Con estos parámetros, la doctrina ha sostenido que para determinar si hay quebrantamiento del principio de igualdad a partir del supuesto de hecho a enjuiciar, deben efectuarse tres deducciones lógicas ${ }^{44}$ :

a) Constatar que los términos de comparación son homogéneos.

b) Debe quedar verificada la distinta tributación en cada uno de los casos.

c) Hay que determinar la falta de justificación de esta disparidad; o que, estando justificada, no resulte proporcional al fin perseguido.

La doctrina no está de acuerdo sobre la completa identidad entre los arts. 14 y 31.1 C.Pol.Esp., sobre todo a raíz de la postura del TCE de separar ambas categorías, aunque al parecer manifiesta un mayor compro-

42 STCE 214/1994 (de 14 de julio), FJ 80: "Sobre el alcance del principio de igualdad ante la Ley este Tribunal ha elaborado en numerosas Sentencias una matizada doctrina cuyos rasgos esenciales pueden resumirse como sigue: a) no toda desigualdad de trato en la Ley supone una infracción del articulo 14 C.Pol.Esp., sino que dicha infracción la produce solo aquella desigualdad que introduce una diferencia entre situaciones que pueden considerarse iguales y que carece de una justificación objetiva y razonable; b) el principio de igualdad exige que a iguales supuestos de hechos se apliquen iguales consecuencias juridicas, debiendo considerarse iguales dos supuestos de hecho cuando la utilización o introducción de elementos diferenciadores sea arbitraria o carezca de fundamento racional; c) el principio de igualdad no prohibe al legislador cualquier desigualdad de trato, sino solo aquellas desigualdades que resulten artificiosas o injustificadas por no venir fundadas en criterios objetivos y suficientemente razonables de acuerdo con criterios o juicios de valor generalmente aceptados; d) por último, para que la diferenciación resulte constitucionalmente lícita no basta con que lo sea el fin que con ella se persigue, sino que es indispensable además que las consecuencias juridicas que resultan de tal distinción sean adecuadas y proporcionadas a dicho fin, de manera que la relación entre la medida adoptada, el resultado que se produce y el fin pretendido por el legislador superen un juicio de proporcionalidad en sede constitucional, evitando resultados especialmente gravosos o desmedidos" [STCE 76/1990, FJ 9. A)].”

43 ESEVERri (2006) 33.

44 ESEVERRI (2006) 33. 
miso a considerar la igualdad tributaria como una aplicación del principio general de igualdad al ámbito tributario ${ }^{45}$.

Esto enlaza, por cierto, al problema suscitado en el TCE en orden a no acoger, por regla general, los recursos de amparo constitucional en defensa de la igualdad tributaria por estimar que este derecho se encuentra consagrado en el art. 31.1 C.Pol.Esp. y que, por tanto, presenta autonomía en relación a la igualdad genérica del art. 14 C.Pol.Esp., y de este modo, se encuentra fuera del ámbito de tutela de este recurso.

De acuerdo a esta posición, se ha sostenido que el art. 14 C.Pol.Esp. consagraría la igualdad negativa (interdicción de las discriminaciones arbitrarias); mientras que, el art. 31.1 C.Pol.Esp, la igualdad positiva (a tratar como desigual a los desiguales) ${ }^{46}$.

El TCE ha defendido la diferencia entre los arts. 14 y 31 constitucionales, para lo cual ha creado un criterio diferenciador de ambas especies de igualdad, sobre la idea de una distinción de unas circunstancias objetivas y subjetivas presentes en ambos casos.

De acuerdo a esta tesis, la primera de dichas normas consagraría la igualdad ante la ley, apreciada como una igualdad subjetiva que trata de impedir discriminaciones que pueda efectuar la ley en razón de circunstancias o cualidades que acompañan el carácter o condición del individuo, tales como el sexo, la raza, etc., y busca proteger derechos y libertades inherentes a la condición de la persona ${ }^{47}$.

$\mathrm{Al}$ contrario, en la STCE 159/1997 FJ $3^{\circ}$ (doctrina reiterada en las SSTCE 183/1997, FJ 30; 55/1998, FJ $3^{\circ}$ y 71/1998, FJ 40), se ha ido acuñando una regla según la cual la igualdad en el ámbito tributario obedecería a razones objetivas $^{48}$. Se trataría de una igualdad en la ley pero referida a dicha esfera, que se evalúa comparando dos situaciones de hecho y discurriendo sobre las circunstancias objetivas definidas en la ley, sobre si la capacidad económica gravada en el impuesto de que se trate (atinentes a la renta o los ingresos de los sujetos) ha sido considerada de manera diferente sin que existan razones justificadoras válidas. De este modo, este principio permite evitar "tratamientos diferentes cuando realidades económicas contempladas en la norma de que se trate resulten ser idénticas", por ello se trataría de una igualdad objetiva "que impide, en atención a la capacidad económica de los ciudadanos, que la norma tributaria conside-

45 Fernández (1997) 101. Este autor señala que la STCE 76/1990, de 26 de abril, sintetiza la jurisprudencia constitucional en materia de igualdad.

46 Gorospe Oviedo, Juan Ignacio y Herrera Molina, Pedro Manuel (2007). "La virtualidad del principio de capacidad económica en el ordenamiento tributario español". En Albiñana García-Quintana, César; González García, E.; Ramallo Massanet, Juan; Lejeune Valcárcel, Ernesto; Yábar Sterling, A. (coordinadores): Estudios en homenaje al profesor Pérez de Ayala. Madrid: Dykinson, p. 32.

47 Eseverri (2006) 30.

48 Medina (2010). 
re de forma disímil situaciones acreditadas de capacidad económica que se hallan en un plano semejante", vinculado, por ejemplo, al volumen de renta que sea semejante en dos contribuyentes y mientras no existan circunstancias objetivas que justifiquen distinción legal alguna ${ }^{49}$ :

"De ello se desprende con claridad que la posible inconstitucionalidad que la recurrente imputa al artículo 38.2.2 de la Ley 5/1990, por su eventual contradicción con el principio de igualdad, no residiría realmente en una discriminación contraria al artículo 14 C.Pol.Esp por estar basada en una diferenciación de índole subjetiva, sino en una desigualdad fundada en elementos objetivos, que es la contemplada por el artículo 31.1 C.Pol.Esp. Y, por tanto, la conclusión última solo puede ser, a la luz de la doctrina antes expuesta, que nos encontramos ante una eventual desigualdad no susceptible de ser corregida por el cauce del presente proceso de amparo, aunque pueda serlo, en su caso, por el de otros procesos constitucionales, como el recurso o la cuestión de inconstitucionalidad" (STCE 159/1997 FJ 30).

El TCE, ya con su sentencia No 27/1981, sostenía que el principio de igualdad tributaria no puede ser reconducido de modo simple al art. 14 C.Pol.Esp, por su vinculación con los principios de capacidad económica y progresividad tributaria, e incluso lo aleja de él debido a la necesidad de incorporar una "cierta desigualdad cualitativa" a través de la progresividad global del sistema tributario a fin de lograr metas de redistribución de la renta ${ }^{50}$ (nótese que la C.Pol.Esp consagra tales funciones del Estado en diversas normas, tales como el art. 9.2, el art. 40.1, y el art. 131.1, todos de la C.Pol.Esp):

"...Aunque una definición válida de lo que debe entenderse por justo, a efectos tributarios, sería una tarea que rebasa el planteamiento que aquí hemos de hacernos, lo que no puede soslayarse es que el legislador constituyente ha dejado bien claro que el sistema justo que se proclama no puede separarse, en ningún caso, del principio de progresividad ni del principio de igualdad. Es por ello -porque la igualdad que aquí se reclama va íntimamente enlazada al concepto de capacidad económica y al principio de progresividad- por lo que no puede ser, a estos efectos, simplemente reconducida a los términos del artículo 14 de la Constitución: una cierta desigualdad cualitativa es indispensable para entender cumplido este principio. Precisamente la que se realiza mediante la progresividad

EsEVERRI (2006) 31.

Medina (2010). Este autor recuerda que la consecuencia (y también probablemente su causa) de esta interpretación es la de excluir de la esfera del recurso de amparo a las cuestiones vinculadas a la igualdad en el ámbito fiscal, como lo ha declarado el TCE (STCE 54/1993). Para Eseverri en lo recién citado, la desigualdad legal, porque se debe a razones objetivas enraizadas en el tratamiento legal de las capacidades económicas, debe ser combatida ante el TCE mediante la cuestión de inconstitucionalidad de la ley con ocasión de los actos singulares dictados en aplicación de la ley tributaria discriminadora. 
global del sistema tributario en que alienta la aspiración a la redistribución de la renta" (STCE 27/1981, FJ 4º).

Otro asunto relevante para los fines del presente trabajo, y teóricamente complejo, está constituido por la relación entre capacidad económica e igualdad, el que ha sido resuelto a través de dos diversas vías o tesis, dependiendo de la concepción que se asuma del principio de igual$\mathrm{dad}^{51}$.

a) Tesis de la capacidad económica como medida de la igualdad. Aquí, la máxima de la igualdad presenta un carácter formal y abstracto, limitado a la afirmación de que dos situaciones iguales deben recibir el mismo trato, pero no indica el criterio que debe usarse para determinar cuándo son iguales o distintas las situaciones en análisis. $\mathrm{Al}$ carecerse de un criterio para evaluar las situaciones, se debe recurrir a una medida externa a la máxima de la igualdad, el cual en materia tributaria estaría constituido por el principio de capacidad económi$\mathrm{ca}^{52}$.

b) Tesis de la capacidad económica como expresión (concreción) de la igualdad en el ámbito tributario. El principio de igualdad presenta como contenido, la prohibición de las discriminaciones arbitrarias, cuales son las no justificadas, no razonables, contrarias a la conciencia jurídica o la naturaleza de las cosas, entroncando con el Derecho Natural ${ }^{53}$. En este caso, el principio de capacidad funciona del mismo modo que el de igualdad, constituye un criterio para el enjuiciamiento de la legislación fiscal desde la perspectiva del principio de igualdad $^{54}$.

El TCE ha aplicado conjuntamente los principios de igualdad y capacidad económica, y los ha considerado en los dos sentidos indicados, aunque ha resuelto que este último no puede ser apreciado como el único principio vinculado a la igualdad ${ }^{55}$.

51 Palao Taboada, Carlos (1995). "Los principios de capacidad económica e igualdad en la jurisprudencia del Tribunal Constitucional español”. Civitas, Revista Española de Derecho Financiero, 88, Madrid, p. 20.

52 Nótese que esto ha sucedido en Chile, pero ha sido la ley el criterio externo incorporado como medida de la igualdad formal y abstracta.

53 Gallego (2003) 140, sostiene que con esto, el contenido material del principio de igualdad queda indeterminado ex ante, pero solventa algunos problemas de aplicación del principio de capacidad económica, tales como el ámbito de aplicación a los diferentes tributos y la cuestión de los fines extrafiscales en los tributos.

54 Palao TABoada, Carlos (2005). "Nueva visita al principio de capacidad contributiva”. Civitas, Revista Española de Derecho Financiero, 124, p. 777.

55 Palao (1995) 31. 
C) Una característica destacable del principio de progresividad es su raigambre económica, y encuentra fundamento en la equidad vertical. La progresión del tributo implica un tratamiento diferenciado entre diferentes niveles de capacidades contributivas. Ahora, habiéndose incluido en la C.Pol.Esp, demanda una elaboración jurídica por parte de los juristas ${ }^{56}$.

Este principio se encuentra ligado a la tasa del tributo (en la doctrina española se le denomina con más precisión "tipo impositivo"), y busca que la carga fiscal se reparta de un modo más equitativo que la mera proporción de la riqueza, aumentando con el acrecentamiento de la capacidad contributiva (STCE 27/1981, FJ 5º). De este modo, materializa el principio de solidaridad, pues persigue una "más justa distribución de la riqueza" con el objetivo de promover la igualdad real y efectiva de todas las personas, que es un objetivo esencial del Estado Social ${ }^{57}$. En cuanto presenta una finalidad redistributiva, se ha dicho que la progresividad persigue fines extrafiscales ${ }^{58}$.

Contrariamente a las opiniones vertidas en Chile, en España se ha sostenido que este principio no es reconducible sin más al derecho de igualdad genérico ${ }^{59}$ aunque, por otro lado, constituye una exigencia de los principios de igualdad efectiva y capacidad económica, ya que el deber de acudir al sostén de los gastos públicos se intensifica a medida que aumenta la capacidad económica del contribuyente ${ }^{60}$ (a esta nota se le denomina "principio de intensidad del gravamen", y es uno de los elementos del principio de capacidad económica).

Por esto, se ha defendido que la progresividad se vincula a una igualdad cuantitativa, no a la cualitativa (ex artículo 14 C.Pol.Esp). En efecto, dice relación con el reparto más equitativo de la carga necesaria para solventar los gastos públicos, y en cuanto tal es un criterio de cuantificación de la obligación tributaria individual ${ }^{61}$.

La progresividad opera de dos modos: a través de aumento de la tasa del gravamen conforme aumenta la capacidad económica (método cuantitativo); o aplicando tasas diferenciadas de acuerdo a la naturaleza de los bienes transables (según se trate de suntuarios, o de primera necesidad). También se distinguen tasas progresivas continuas y escalonadas.

En efecto, y si bien este principio actúa claramente en los tributos directos, también se expresa en los impuestos indirectos con la tributación diferenciada (disminuida, eliminada o incluso, con bonificaciones) 
conforme se trate de bienes de primera necesidad y bienes suntuarios o lúdicos ${ }^{62}$.

La jurisprudencia constitucional ha sostenido, desde la STCE $77 / 1985$, de 27 de junio, que es el sistema tributario en su conjunto el que debe ajustarse a este principio, más que cada figura impositiva en particular ${ }^{63}$.

Aun cuando existen opiniones en todos los sentidos ${ }^{64}$, es razonable pensar que si las exigencias de justicia fiscal solo se predicaran sobre el conjunto del sistema y no sobre cada figura que lo integra, se desvanecerían completamente las garantías de los valores fundamentales que están en la base de los límites de la imposición ${ }^{65}$, ya que la función primaria del principio es la de enjuiciar cada ley en particular ${ }^{66}$. Del mismo modo en que cada tributo debe ser analizado a la luz de los principios materiales, en definitiva, del mismo modo debe ser evaluado todo el sistema tributario.

D) A diferencia de lo que se concibe en Chile, el principio de no confiscatoriedad no enlaza directa o principalmente con la tutela de la propiedad, con la que, por cierto, reconoce vínculos.

Confiscación significa "privación de bienes por parte del poder público para aplicarlos al fisco sin compensación alguna”, y en el ámbito tributario tiene por efecto evitar la absorción total de la fuente económica o

62 ESEVERri (2006) 36.

63 EsEVErri (2006) 37.

64 Para algunos autores, Es el sistema tributario como un conjunto (y no con cada figura tributaria en particular) el que debe responder al principio de capacidad económica, lo que así se traduce en el deber constitucional de contribuir [Queralt, Martín; Lozano, Carmelo; Tejerizo, José; Casado, Gabriel (2007) Curso de Derecho Financiero y Tributario. 18 $8^{\mathrm{a}}$ edición. Madrid: Tecnos, p. 127.]; Fernández Segado considera que los principios materiales de justicia tributaria se proyectan sobre el conjunto del sistema tributario y no solo sobre todas y cada una de las diferentes figuras que lo integran. [Calvo Ortega, Rafael (2006) Curso de Derecho financiero y Derecho tributario. Parte general. 10a edición. Madrid: Thomson-Civitas, p. 52], parece situarse en el otro extremo, al sostener que el principio de capacidad económica retrata una "situación subjetiva patrimonial en relación con obligaciones dinerarias determinadas", aunque se trataría de un planteamiento "puramente lógico: tiene capacidad económica el titular de una situación patrimonial concreta y suficiente frente a la obligación tributaria que se derive de esa misma situación”, por lo que la capacidad económica se predica ante una obligación tributaria concreta. Este principio se extiende a todos los tributos -tasas, contribuciones especiales e impuestos- y a todas las personas, jurídicas o físicas. Para Gallego (2003) 118, el principio de capacidad económica opera, sin ninguna reserva, frente al sistema tributario en su conjunto y no frente a cada figura impositiva particular, pues de otro modo se desvirtuaría el concepto constitucional de justicia tributaria.

65 Casado Ollero, Gabriel (1982). "El principio de capacidad y el control constitucional de la imposición indirecta (II). El contenido constitucional de la capacidad económica”. Civitas, Revista Española de Derecho Financiero, No 34, p. 219.

66 Palao Taboada, Carlos (1976). "Apogeo y crisis del principio de capacidad contributiva”. Estudios juridicos en homenaje al profesor Federico de Castro, Vol. II, p. 397. 
riqueza del contribuyente ${ }^{67}$. Sin embargo, hablar de "no confiscatoriedad" se aprecia como una paradoja o contradicción precisamente porque el tributo constituye una detracción de riqueza, que no exige contraprestación directa debido a que precisamente uno de los fundamentos del sistema tributario justo es la redistribución de la riqueza (de la propiedad privada, si bien reconociéndole valor y otorgándole tutela), lo que se encuentra justificado en el marco del Estado Social ${ }^{68}$. Por ello debe enfatizarse que lo que la C.Pol.Esp exactamente persigue es que el tributo no tenga un efecto confiscatorio.

Aunque no existe porcentaje relativo al riguroso límite legítimo de dicha detracción, se encuentra restringida por el respeto del principio de capacidad económica, tanto en su demarcación mínima como máxima. En efecto, el resguardo de un espacio de indemnidad tributaria como es el mínimo exento personal y familiar (elemento del principio de capacidad económica, como se verá), exige por un lado que no se sustraiga toda la riqueza y a su vez que la exigida solo sea una parcialidad de la riqueza del contribuyente.

El principio constitucional de justicia (general o tributaria) también opera, en cuanto la total ablación de la riqueza resulta contrario a este; y por otro lado, el efecto de la aplicación de los tributos debe ser ponderado con la ejecución del gasto de acuerdo a criterios de justicia (con lo que resultan contraprestaciones públicas ${ }^{69}$ que atenúan el esfuerzo individual derivado del cumplimiento de las obligaciones tributarias). De ahí que el principio que opera en el ámbito tributario no sea tanto el de tutela de propiedad como el de capacidad económica, y en definitiva el de justicia tributaria.

Este principio, entonces, constituye un criterio de evaluación constitucional referido al resultado de la imposición, no prohibiendo propiamente la confiscación, sino el alcance confiscatorio de los tributos ${ }^{70}$ (aunque presenta la dificultad de su determinación cuantitativa $)^{71}$.

PAUNer (2001) 176.

PAUner (2001) 179.

La esencial vinculación entre ingresos y gastos públicos en el contexto de un sistema financiero justo ha sido destacada por diversos autores y por el propio TCE (STCE 76/1990, de 26 de abril). Fernández Segado ha dicho que "el principio de capacidad económica, regla nuclear en el reparto y distribución de la carga tributaria, debe combinarse estrechamente con los principios de justicia en el gasto público" [FERnÁNDEZ (1997) 81]. Esta relación también es destacada por otros autores. Comparar con Albiñana García-Quintana, César (1996). "El gasto público". En Alzaga Villamil, Óscar (coordinador): Comentarios a la Constitución Española de 1978, Tomo III. Madrid: Cortes Generales-Editoriales de Derecho Reunidas. Disponible en Base de datos V LEX; Id. vLex: VLEX-331157. [Fecha de visita en agosto de 2011], p.412.

CASAdo (1982) 193.

Se ha dicho que busca evitar que, con carácter punitivo, se prive de los bienes a las personas a favor del Estado. Pero dicha aproximación estaría errada, en cuanto ello se refiere al 
Se ha asegurado que la detracción legítima a las economías privadas que implica el deber de contribuir, no puede producirse de modo desproporcionado, arbitrario y voraz, en el sentido de ejercer una presión fiscal sobre el patrimonio de los particulares exigiéndoles un esfuerzo superior al juicio racional y al buen quehacer de los poderes públicos ${ }^{72}$. Asimismo, y con el pretexto del deber de contribuir, el Estado tampoco puede llegar a agotar la riqueza imponible, que es el sustrato o base de la imposición ${ }^{73}$.

La máxima de no confiscatoriedad presenta diferentes interpretaciones y ha sido objeto de diferentes valoraciones ${ }^{74}$.

Para algunos, constituye una garantía frente a posibles abusos en la progresividad del sistema, pues, a través de la misma se puede llegar a atentar contra la capacidad económica que la sustenta, de tal modo que impide una interpretación extremista de este principio que conduzca a lesionar el derecho de propiedad. Desde esta perspectiva, la prohibición de confiscatoriedad debe contemplarse en función de la justicia del sistema tributario y no únicamente en función de la defensa de la propiedad, ya que, en el contexto constitucional espańol, no constituye una vía directa de garantía de la propiedad, sino una garantía del sistema tributario frente a posibles desviaciones ${ }^{75}$.

Otros lo ven como una aplicación del principio de que el tributo debe sujetarse a la capacidad contributiva del contribuyente, de modo tal que un tributo que no se adecua a este último es confiscatorio.

Un tercer grupo estima que solo se trata de una reiteración del concepto de justicia tributaria (vid. STCE 150/1990, FJ $\left.9^{\circ}\right)^{76}$.

Con todo, existen matizaciones que conducen incluso hasta su cuestionamiento como principio, aunque se reconozca su carácter de límite del poder tributario ${ }^{77}$.

Pese a lo hasta ahora planteado, debe reconocerse su conexión con el derecho de propiedad, en el sentido de que lo confiscatorio es toda exigencia impositiva que intervenga dicho derecho sin encontrar sostén en causas de interés general ${ }^{78}$ ni en la capacidad económica del contribuyente.

\footnotetext{
decomiso, puesto que la confiscación es solo la privación de bienes a una persona para aplicarlos al Fisco [Gallego (2003) 181].

ESEVERri (2006) 37.

Gallego (2003) 194.

Gallego (2003) 184.

FERnÁNDEZ (1997) 109.

Medina (2010).

Para Calvo (2006) 60, el principio de no confiscatoriedad sería un límite al poder tributario y no un principio con una esencia creativa y susceptible de ser usado como una herramienta metodológica. Para otros, constituye límite extremo (derivado del derecho de propiedad) para la progresividad del tributo, pero ello es tautológico, porque la confiscatoriedad está fuera del ordenamiento jurídico [QUeralt y otros (2007) 122].

ESEVERRI (2006) 38.
} 
Como se ha sostenido suficientemente por la doctrina, el deber de contribuir se fundamenta en la solidaridad y, además, en la función social de la propiedad. Siempre implica una detracción de la riqueza particular, pero a través de unos procedimientos, una configuración y unos fines legítimos. Por ello, el TCE ha mantenido que es de la esencia del deber de contribuir el que este constituya una limitación de la propiedad ${ }^{79}$.

En su configuración constitucional, el derecho de propiedad se encuentra reconocido en el art. 33, y sujeto al interés general, conforme al art.128.1:

\section{Artículo 33.}

1. Se reconoce el derecho a la propiedad privada y a la herencia.

2. La función social de estos derechos delimitará su contenido, de acuerdo con las leyes.

3. Nadie podrá ser privado de sus bienes y derechos sino por causa justificada de utilidad pública o interés social, mediante la correspondiente indemnización y de conformidad con lo dispuesto por las leyes.

Articulo 128.1. Toda la riqueza del pais en sus distintas formas y sea cual fuere su titularidad está subordinada al interés general.

La doctrina reconoce la enorme complejidad que existe para visualizar reglas abstractas de validez general que permitan identificar en los casos concretos cuando se produce un quebrantamiento del principio en análisis ${ }^{80}$. Hay quienes plantean que cabe claramente su procedencia frente a todos los tributos, y con él debe evaluarse cada tributo en particular y asimismo a todo su conjunto ${ }^{81}$. Otros sostienen que solo vincula al conjunto de tributos, es decir, a todo el sistema tributario.

Al respecto, la sentencia del Tribunal Constitucional español 150/1990 desarrolló algunas directrices generales para aplicar este principio, en cuanto que la prohibición de confiscatoriedad (como el principio de capacidad económica) constituye un mandato para "no agotar la riqueza imponible -sustrato, base o exigencia de toda imposición- so pretexto del deber de contribuir". Agrega la sentencia que este límite constitucional se establece con referencia al resultado de la imposición, con la aplicación de las diversas figuras tributarias vigentes. Pone como ejemplo evidente del tributo confiscatorio, un Impuesto sobre la Renta de las Personas Físicas cuya progresividad alcanzara un tipo medio de gravamen (tasa) del cien por ciento de la renta, si bien sustenta que excluido este

\footnotetext{
79 STCE 150/1990: "De hecho, en materia fiscal, la confiscación no supone la privación imperativa, al menos parcial, de propiedades, derechos patrimoniales o rentas sin compensación, ya que este tipo de privación o exacción es, en términos generales, de esencia al ejercicio de la potestad tributaria y al correlativo deber de contribuir al sostenimiento de los gastos públicos".

80 Medina (2010).

81 Gallego (2003) 198.
} 
límite absoluto asume la dificultad de situar, con criterios técnicamente operativos, la frontera en la que lo progresivo, lo justo, degenera en confiscatorio ${ }^{82}$.

De esto se extrae que, para el TCE, lo prohibido por la C.Pol.Esp, respecto del tributo no es la confiscación, sino el alcance confiscatorio, de lo que se deriva que para declararse la inconstitucionalidad de un tributo no se requiere la limitación del $100 \%$ de la fuente de riqueza, aunque, como se ha comunicado, el TCE reconoce la dificultad de establecer los límites precisos a partir del cual un tributo tiene dicho alcance confiscatorio.

Respecto de la posibilidad de determinar un techo máximo preciso del tributo, un limite preciso a la carga tributaria, más allá del cual el tributo adopte carácter (alcance) confiscatorio, es conveniente referirse a la sentencia del Tribunal Constitucional Alemán de fecha 22 de junio de 1995 relativa al Impuesto sobre el Patrimonio, en que este sostuvo que la carga tributaria que el contribuyente debe soportar no puede superar el $50 \%$

82 STCE 150/1990, FJ 90: "El examen de esta alegación viene, en efecto, condicionado por la interpretación que haya de darse al principio de no confiscación en materia fiscal, cuestión que dista de hallarse doctrinalmente clarificada, al contrario de lo que ocurre, por ejemplo, en el ámbito penal o en el de la institución expropiatoria lato sensu. De hecho, en materia fiscal, la confiscación no supone la privación imperativa, al menos parcial, de propiedades, derechos patrimoniales o rentas sin compensación, ya que este tipo de privación o exacción es, en términos generales, de esencia al ejercicio de la potestad tributaria y al correlativo deber de contribuir al sostenimiento de los gastos públicos. Por ello hay quien identifica dicho principio con el de capacidad contributiva, de suerte que sería confiscatorio todo tributo que no se fundara en este; hay quien considera que es una reiteración del principio de justicia tributaria; y hay finalmente quien opina que constituye un limite -por más que indeterminado y de difícil determinación-al principio de progresividad del sistema tributario. Tiene declarado este Tribunal, ya en su STCE 27/1981, que capacidad económica, a efectos de contribuir a los gastos públicos, tanto significa como la incorporación de una exigencia lógica que obliga a buscar la riqueza alli donde la riqueza se encuentra. A ello cabe añadir ahora que la prohibición de confiscatoriedad supone incorporar otra exigencia lógica que obliga a no agotar la riqueza imponible-sustrato, base o exigencia de toda imposición- so pretexto del deber de contribuir; de ahi que el limite máximo de la imposición venga cifrado constitucionalmente en la probibición de su alcance confiscatorio. $Y$ dado que este limite constitucional se establece con referencia al resultado de la imposición, puesto que lo que se prohibe no es la confiscación, sino justamente que la imposición tenga "alcance confiscatorio", es evidente que el sistema fiscal tendría dicho efecto si mediante la aplicación de las diversas figuras tributarias vigentes, se llegara a privar al sujeto pasivo de sus rentas y propiedades, con lo que además se estaría desconociendo, por la vía fiscal indirecta, la garantía prevista en el artículo 33.1 de la Constitución: como sería asimismo, y con mayor razón, evidente el resultado confiscatorio de un Impuesto sobre la Renta de las Personas Físicas cuya progresividad alcanzara un tipo medio de gravamen del 100 por 100 de la renta. Pero, excluidos aquel limite absoluto y esta evidencia aritmética, y asumiendo la dificultad de situar con criterios técnicamente operativos la frontera en la que lo progresivo o, quizá mejor, lo justo, degenera en confiscatorio, si resulta posible rechazar que la aplicación del recargo autonómico de que tratamos conculque el artículo 31.1 de la Constitución por su eventual superación de los limites cuantitativos o porcentuales establecidos por el legislador estatal para el Impuesto sobre la Renta; pues en tal caso no podría establecerse recargo alguno, o bien habría ello de hacerse en detrimento de los principios de igualdad y progresividad de los tributos que asimismo proclama el artículo 31.1 de la Constitución". 
de sus ingresos, incluyendo los impuestos indirectos ${ }^{83}$, en razón de que conforme a la Constitución alemana, la propiedad privada sirve por igual al beneficio privado y al interés público, que el legislador debe preservar los fundamentos económicos de la vida privada, y que el impuesto al patrimonio también debe proteger al matrimonio y la familia ${ }^{84}$. En esta ocasión, la decisión del Tribunal Alemán manifiesta el carácter de sistema de los tributos, que es el que finalmente resulta evaluado bajo el concepto de "carga tributaria global" 85 .

En España el Tribunal Constitucional no ha construido una regla que muestre cuándo el sistema impositivo alcanza el carácter de confiscatorio (conforme a la STCE 150/1990 de 4 de octubre, FJ 9º, citada), lo que probablemente se debe a que su texto constitucional (art. 128) subordina toda la riqueza al interés general, aunque se ha dicho que no cabe indicar como límite de inconstitucionalidad la cifra de 50\% ni tipos medios (tasas intermedias, decimos en Chile) entre dicha cifra y el $100 \%{ }^{86}$.

También hay un límite máximo, protegido por el principio de no confiscatoriedad (STCE 150/1990), el cual supone la incorporación de una exigencia lógica de no agotar la riqueza con el pretexto del deber de contribuir. Tampoco es un límite preciso, no existe una cifra. La cifra del $50 \%$ sugerida por el Tribunal Constitucional Alemán tampoco es clara, pues no indica, por ejemplo, si corresponde a la renta neta o bruta (íntegra). Por otro lado, debe considerarse tanto la presión fiscal directa como la indirecta, los impuestos sobre los bienes, y los costes necesarios para el cumplimiento de las normas tributarias (la obligación tributaria principal o material y las accesorias o formales).

E) El principio de capacidad económica ${ }^{87}$ ha sido reconocido como el principio rector en el ámbito de la justicia tributaria ${ }^{88}$. A diferencia de los otros principios, es exclusivo del ámbito tributario.

83 Herrera Molina, Pedro Manuel (1997). "El principio de capacidad económica en Alemania y su relevancia para el Derecho español". Noticias de la Unión Europea, 150, p. 40.

84 Herrera (1996) 1.036

85 Herrera (1996) 1.043. En el caso español, como se ha dicho, su Constitución consagra también un sistema de tributos (artículo 31.1), y en cuanto tal, el resto de los principios ya indicados deben coordinarse en torno a dicha idea. Reflexiona Herrera (1996) 1.045, afirmando que la citada sentencia alemana constituyó un giro jurisprudencial, que previamente solo calificaba de inconstitucionales los impuestos "estranguladores" o "sofocantes", es decir, "aquellos que en la generalidad de los casos gravaran desmesuradamente a los contribuyentes menoscabando radicalmente sus relaciones patrimoniales".

86 HERRERA (1996) 1.044.

87 La doctrina chilena usualmente se refiere a capacidad contributiva. En algunos sitios (como en Italia) se usa el término capa capacidad contributiva, para definir la capacidad económica gravable o aquella capacidad económica superior al mínimo vital. Los debates que al respecto se han producido en Espańa son explicados por PAUner (2001) 157, nota 383.

88 Cabe señalar que el TCE ha reiterado que "a efectos de contribuir a los gastos públicos, tanto significa como la incorporación de una exigencia lógica que obliga a buscar la riqueza allí 
Puede definirse como la aptitud para concurrir a las cargas públicas (tributos) manifestada en la posesión de riqueza económica, lo que implica tanto que constituye condición como fundamento excluyente de la obligación de contribuir. La capacidad económica dice relación con la potencialidad económica vinculada a la titularidad y disponibilidad de la riqueza ${ }^{89}$; con la aptitud, la posibilidad real, la suficiencia de un sujeto de derecho para hacer frente a la exigencia de una obligación tributaria con$\operatorname{creta}^{90}$. $\mathrm{va}^{91}$.

Es posible distinguir una capacidad económica absoluta y otra relati-

La primera se concibe como la capacidad abstracta para concurrir al sostenimiento de las cargas públicas, y da cuenta de índices directos o indirectos de manifestación de riqueza, constituyendo el supuesto de hecho base del tributo (titularidad de un patrimonio; percepción de una renta; acto de consumo, tráfico o circulación de bienes). Su función es garantizar que solo se establezcan tributos sobre actos, hechos o negocios indicativos de capacidad económica ${ }^{92}$ en cuanto indices o representaciones de riqueza ${ }^{93}$ (es un límite del tributo frente al legislador ${ }^{94}$ pues lo obliga a construir un sistema tributario y unos tipos impositivos congruentes con sus criterios ${ }^{95}$ ). En tal sentido, impide intentar gravar riquezas ficticias o

donde la riqueza se encuentra" (desde STC 27/1981, FJ 4). Se ha interpretado que el TCE ha sustentado una concepción de la capacidad económica como real, individual, efectiva, cierta o existente (desde SSTCE 27/1981), pero también como potencial, puesta de manifiesto en la generalidad de los supuestos contemplados por el legislador al crear un impuesto (desde STC 37/1987); y que este principio se vulnera si se pretende gravar rentas inexistente o ficticia (STC 221/1992, FJ 4º) o aparentes o no reales (STC 194/2000, FJ 7º).

Fernández (1997) 98. Para Carrera Raya, capacidad económica es un término más adecuado que el de capacidad contributiva, la cual es una calificación hecha por el legislador [CARrera Raya, José Francisco (1994) Manual de Derecho Financiero, Vol. I: Derecho Financiero y Teoría de los Ingresos Públicos. Madrid: Tecnos].

90 Calvo (2006) 52.

91 Distinción que interpreto como análoga a la de Casado Ollero, entre capacidad económica como, por un lado, fuente de la imposición y, por otro, como criterio de contribuir al sostenimiento de los gastos públicos. En: Casado (1982).

92 Collado-Moreno (2007) 38.

93 Se ha dicho, con razón, que sin riqueza no hay tributos. Solo la riqueza debe tributar (STCE 37/1987).

94 Calvo (2006) 52. Palao Taboada niega relevancia al principio de capacidad económica, señalando que el principio de capacidad económica "desde la perspectiva estrictamente jurídica... tiene la función relativamente modesta de limite al legislador: una función esencialmente negativa de resistencia al poder" [PALAo (2005) 769].

95 Así lo ha declarado el Tribunal Constitucional. STCE 96/2002, de 25 de abril, FJ 70: "Esta recepción constitucional del deber de contribuir al sostenimiento de los gastos públicos según la capacidad económica de cada contribuyente configura un mandato que vincula no solo a los ciudadanos sino también a los poderes públicos (STC 76/1990, de 26 de abril, F. 3) ya que, si los unos están obligados a contribuir de acuerdo con su capacidad económica al sostenimiento de los gastos públicos, los poderes públicos están obligados, en principio, a exigir esa contribución a 
inexistentes ${ }^{96}$, fricciona con la doble imposición interna, con exenciones sin justificación constitucional, con el gravamen de incrementos monetarios nominales ${ }^{97}$ o sobre adquisiciones instrumentales ${ }^{98}$.

Asimismo, este principio constituye la razón de ser (la ratio) o fundamento que justifica el deber de contribuir, es la base del tributo (como lo es el principio del beneficio en las tasas y contribuciones especiales; si bien la capacidad económica se extiende a todos los tributos, incluidos éstos $\left.{ }^{99}\right)$. Se debe porque se tiene capacidad económica para soportar el gravamen ${ }^{100}$, es el punto de partida sobre el cual se construye un sistema tributario justo ${ }^{101}$.

Por su parte, la capacidad económica relativa es aquella que orienta o modula la concreta carga tributaria que un contribuyente debe soportar. Constituye la medida, razón o proporción de cada contribución, individual de los sujetos obligados al sostenimiento de los gastos públicos. Se debe de acuerdo o según a la capacidad que se tiene ${ }^{102}$, lo que debe reflejarse en el hecho imponible y en los elementos esenciales que determinan la cuantificación de la deuda tributaria ${ }^{103}$.

En cuanto a su estructura, consta de tres extremos ${ }^{104}$ :

todos los contribuyentes cuya situación ponga de manifiesto una capacidad económica susceptible de ser sometida a tributación".

96 ESEVERri (2006) 29.

97 Pero esto no ha estado exento de problemática, que Falcon y Tella describe con ocasión del comentario a la Ley de IRF 40/1998, de 20 de diciembre (BOE 10 diciembre 1998), por no tener en cuenta absoluto la corrección monetaria (el factor inflación) respecto de ciertos elementos patrimoniales, y por no habilitar siquiera al reglamento para introducir medidas correctoras, lo que resulta claramente inconstitucional, por cuanto, como ha sostenido el TCE la existencia de coeficientes correctores 'responde a la naturaleza del impuesto sobre la renta, que ha de contemplar incrementos reales no monetarios' (STCE 27/1981, FJ 6), y como sostuvo, en la STCE 221/1992, que, si bien el principio de capacidad contributiva no implica la obligatoriedad de practicar en todo caso correcciones monetarias "tampoco permite al legislador desconocerlo por completo, siempre que la erosión inflacionaria sea de tal grado que haga inexistente o ficticia la capacidad económica gravada por el tributo" [FALCóN Y Tella, Ramón (1998/1999). "El nuevo IRPF y la capacidad contributiva (II): coeficientes de corrección monetaria y rendimientos irregulares". Quincena Fiscal Aranzadi, No 2/1999 BIB 1998\1313].

98 Calvo (2006) 52

99 Calvo (2006) 52.

100 Rodríguez Bereijo, Álvaro (1998). "Jurisprudencia constitucional y principios de la imposición”. Base de Datos Jurídicos Tirant On Line, documento TOL314.024 @www.tirantonline.com [fecha de visita en noviembre, 2011].

101 Albiñana (1996) 412.

102 Rodríguez (1998).

103 Collado-Moreno (2007) 38; Sainz De Bujanda, Fernando (1991) Lecciones de Derecho Financiero, Univ. Complutense de Madrid, 5a edición. Madrid: Facultad de Derecho Universidad Complutense de Madrid, p.107.

104 Herrera Molina, Pedro Manuel (2010). "El Principio de Capacidad Económica”. Disponible en Base de Datos de Conocimientos Jurídicos IUSTEL [fecha de visita julio de 2011]. 
(a) El principio del neto objetivo (estimación objetiva, capacidad objetiva), que exige que solo tribute la renta neta y no las sumas destinadas a obtener los ingresos.

(b) El principio del neto subjetivo (capacidad subjetiva) o de exoneración del mínimo existencial personal y familiar (que beneficia a las personas físicas o naturales ${ }^{105}$ ), por el cual no debe tributarse por las cantidades necesarias para garantizar al contribuyente y a su familia una vida digna, en función de sus circunstancias personales y familiares. El mínimo vital ${ }^{106}$ se ha conceptualizado como aquel conjunto de recursos económicos que en una unidad de tiempo permite atender las necesidades elementales personales y familiares ${ }^{107}$; o como la cantidad que no puede ser objeto de gravamen, por cuanto la misma se encuentra afectada a la satisfacción de las mínimas necesidades vitales de su titular ${ }^{108}$.

Entre las técnicas para satisfacer este mínimo vital, se encuentra la cuota tributaria cero hasta cierto límite, deducciones específicas o determinadas coberturas (de gastos de vida necesarios, bonificaciones por constitución de rentas futuras, ayudas para la adquisición de viviendas o pago de arrendamientos, exención al consumo de productos de primera necesidad, servicios públicos gratuitos, etc.) o la deducción de una cantidad global en el impuesto que grava la renta de las personas ${ }^{109}$.

(c) Determinación de la intensidad del gravamen, por la cual este debe conformarse a la riqueza disponible, y en cuanto tal, procede la tributación progresiva pero sujeta al límite de la no confiscatoriedad.

La doctrina defendió originalmente el carácter de la capacidad económica como principio definidor de la justicia tributaria ${ }^{110}$, influida por la doctrina italiana ${ }^{111}$. El TCE ha destacado desde muy temprano que este principio en Espańa no se contempla como el único criterio

105 Falcón y Tella recuerda que "el mínimo exento y otras exenciones técnicas se han visto siempre como una consecuencia de la capacidad contributiva, que desde las primeras construcciones jurídicas de este principio (Giardina) se entiende como la exigencia de gravar solo la renta actual, neta, individual y disponible". FAlcón y Tella, Ramón (1995). "Exenciones y capacidad contributiva: la paradoja de la exención de los bienes necesarios para el desarrollo de actividades empresariales". Quincena Fiscal Aranzadi, No7/1995.

106 También denominado mínimo existencial, mínimo exento, mínimo de sobrevivencia, mínimo imponible, mínimo no imponible, procura existencial. Gallego (2003) 106.

107 Calvo (2006) 53.

108 Queralt y otros (2007) 126.

109 Calvo (2006) 53. Se han derivado múltiples reglas operativas, entre ellas, que no debe someterse a tributación a los beneficiarios de las ayudas sociales y menos en virtud de recibir estas [CASADO (1982) 192].

110 FERNÁNDEZ (1997) 95.

111 Palao (1976). 
material de justicia tributaria, exclusivo y excluyente (STCE 46/2000 y $134 / 1996)$, sino que aparece vinculado o debe relacionarse a otros principios del sistema tributario ${ }^{112}$ a objeto de realizar el ideal de justicia en el reparto de la carga tributaria (STCE 27/1981, de 20 de julio), por cuanto los principios tributarios del art. 31.1 CE forman un sistema de reglas para dicho objeto ${ }^{113}$.

De este modo, el principio de capacidad económica, se relaciona íntimamente con los demás principios de la tributación.

Constituye la medida de la igualdad, por lo que a iguales índices de capacidad económica debe existir una misma presión tributaria ${ }^{114}$; a distintos niveles de disponibilidad de la riqueza corresponde una tributación distinta (progresividad, encontrándose un límite en la no confiscatoriedad, que evita la extinción de la fuente de la riqueza o de la capacidad

112 Especialmente aquellos más íntimamente entrelazados, a saber, igualdad, progresividad y no confiscatoriedad, los demás del art. 31.1 CE; los de justicia del gasto público, a saber, de asignación equitativa de los recursos públicos, de eficiencia y de economía de la programación y ejecución del gasto, del art. 31.2 CE. De ello, resulta que deben aplicarse principios de justicia tanto en materia de ingreso como de gasto público.

113 La importancia del valor constitucional "sistema", conforme al cual deben configurarse los tributos, ha sido puesto de manifiesto en la doctrina, lo que sintetiza Romero (2005).

114 El Tribunal Constitucional ha puesto de relieve este vínculo en múltiples ocasiones. STCE 193/2004, de 4 de noviembre, FJ 3º: "Pero aún debemos precisar más: se alega un trato desigual ante la ley tributaria. Esta precisión es relevante porque, como venimos reiterando, la igualdad ha de valorarse, en cada caso, teniendo en cuenta el régimen jurídico sustantivo del ámbito de relaciones en que se proyecte. En la materia tributaria es la propia Constitución la que ha concretado y modulado el alcance de su art. 14 en un precepto, el art. 31.1, cuyas determinaciones no pueden dejar de ser tenidas aqui en cuenta, pues la igualdad ante la Ley tributaria resulta indisociable de los principios de generalidad, capacidad, justicia y progresividad, que se enuncian en el último precepto constitucional citado (entre otras, SSTC 27/1981, 20 de julio [RTC 1981, 27], F. 4, y 46/2000, de 17 de febrero [RTC 2000, 46], F. 4). Efectivamente, dicho precepto constitucional dispone que "todos contribuirán al sostenimiento de los gastos públicos de acuerdo con su capacidad económica mediante un sistema tributario justo inspirado en los principios de igualdad y progresividad que, en ningún caso, tendrá alcance confiscatorio". Esta recepción constitucional del deber de contribuir al sostenimiento de los gastos públicos según la capacidad económica de cada contribuyente configura un mandato que vincula, no solo a los ciudadanos, sino también a los poderes públicos (STC 76/1990, 26 de abril [RTC 1990, 76], F. 3) ya que, si los unos están obligados a contribuir de acuerdo con su capacidad económica al sostenimiento de los gastos públicos los otros están obligados, en principio, a exigir en condiciones de igualdad esa contribución a todos los contribuyentes cuya situación ponga de manifiesto una capacidad económica susceptible de ser sometida a tributación (STC 96/2002, 25 de abril [RTC 2002, 96], F.J. 7)." 
económica $\left.{ }^{115}\right)$; y a niveles de riqueza iguales pero cualitativamente diferenciados, corresponde diversa tributación ${ }^{116}$.

También implica que debe tratarse de manera igual las situaciones iguales y discriminarse entre las diferentes ${ }^{117}$.

A su vez, el principio de progresividad tributaria modula la presión fiscal conforme al nivel de capacidad económica de los contribuyentes; y de este modo, ambos constituyen una manifestación del principio de solidaridad tributaria, diferenciando de modo legítimo la presión fiscal de cada contribuyente ${ }^{118}$.

En efecto, la capacidad contributiva debe integrase en el sistema material de valores constitucionales, en el que se encuentra el principio de solidaridad y de igualdad efectiva ${ }^{119}$, el requerimiento de equidad en el gasto público (artículo 31.2 C.Pol.Esp.) ${ }^{120}$ con una finalidad de redistribución de la renta y realización de la justicia material (artículo 9.2, artículo 40.1, artículo 131.1 C.Pol.Esp.) ${ }^{121}$.

En razón de esta integración normativa constitucional, el TCE ha resuelto que los tributos también pueden responder a fines extrafiscales ${ }^{122}$, a criterios económicos y sociales orientados al cumplimiento de fines de interés público garantizados en la Constitución (SSTCE 37/1987; $186 / 1993,289 / 2000,168 / 2004)$ y no solo a la satisfacción de necesidades públicas y de redistribución ${ }^{123}$.

115 En España se han reiterado los fuertes lazos entre los principios de justicia tributaria. Por ejemplo, la STCE 46/2000, de 17 de febrero, sostuvo que: "La igualdad ante la Ley resulta, pues, indisociable de los principios de capacidad económica, asi como de los de generalidad, justicia y progresividad, que se enuncian en el último precepto constitucional citado (SSTC 27/1981, de 20 de julio, FJ 4; 19/1987, de 17 de febrero, FJ 3; 209/1988, de 10 de noviembre, FJ 6; 45/1989, de 20 de febrero, FJ 4; 54/1993, de 15 de febrero, FJ 1, y 134/1996, de 22 de julio, FJ 5)".

116 CARRERa (1994)

117 Queralt y otros (2007) 127. Por dichas razones, es el sistema tributario como un conjunto (y no con cada figura tributaria en particular) el que debe responder al principio de capacidad económica, lo que así se traduce en el deber constitucional de contribuir.

118 ESEVERri (2006) 30.

119 La doctrina comparada ancla el deber de contribuir conforme a la capacidad económica a la solidaridad. Herrera Molina, Pedro Manuel (1998) Capacidad económica y sistema fiscal. Madrid: Marcial Pons, p. 93.

120 FERnÁNDez (1997) 101: "De esta forma, el deber de sostener los gastos públicos pasa del ámbito de la individualización de la carga soportada por cada contribuyente, con el pago de sus impuestos, a un marco más amplio, definido por el deber de solidaridad politica, económica y social que la Constitución garantiza a lo largo de su entramado juridico-institucional".

121 FERNÁNDEZ (1997) 101.

122 Parte de la doctrina cuestiona tanto la vaguedad de este término como su constitucionalidad, ya que la CE en su art. 31 nada dice a su respecto, y las finalidades extrarrecaudatorias serían contrarias a la idea de impuesto justo. Gallego Peragón justifica estos fines del tributo en principios contenidos claramente en la CE. Ver: Gallego (2003) 121.

123 El TCE, en sentencia 37/1987, de 26 de marzo, en su FJ $13^{\circ}$ enfatizó que es constitucionalmente admisible establecer impuestos que, sin desconocer o contradecir el principio de capacidad económica o de pago, respondan principalmente a criterios económicos o sociales 
En cuanto al ámbito de función del principio de capacidad económica, se ha discutido si opera sobre todo el sistema o sobre cada tributo ${ }^{124}$. Sin profundizar en el debate, debe razonarse que si las exigencias de justicia fiscal solo se predicara sobre el conjunto del sistema y no sobre cada figura que lo integra, se desvanecerían completamente las garantías de los valores fundamentales que están en la base de los límites de la imposición $^{125}$, ya que la función primaria del principio es la de enjuiciar cada ley en particular ${ }^{126}$.

Por otro lado, este principio constitucional debe realizarse tanto en el plano normativo como de aplicación de la norma tributaria, en la gestión de cada figura impositiva, pudiendo controlarse constitucionalmente tanto la norma en abstracto como los resultados que se siguen de su aplicación ${ }^{127}$. También implicaría la realización de la ley tributaria por

orientados al cumplimiento de fines o a la satisfacción de intereses públicos que la Constitución preconiza o garantiza, y basta que la capacidad económica exista, como renta real o potencial en la generalidad de los supuestos contemplados por el legislador al crear el impuesto, para que aquel principio constitucional quede a salvo.

Albińana resuelve la cuestión del mismo modo, señalando que el tributo puede considerar fines no fiscales, pero que jamás puede renunciar al principio de capacidad económica sin este abdicaría de su propio fundamento. No constituyen tributos, para este autor, las exacciones públicas que prescinden totalmente de este principio. Por ejemplo, las exacciones públicas cuyo objeto es proteger el medio ambiente, es un caso de "tributos no tributarios". Albiñana (1996) 12.

Para Gosrospe y Herrera, en los tributos redistributivos y con fines extrafiscales el principio de capacidad económica no podría actuar como criterio general de cuantificación, sino como límite garantístico del mínimo existencial y de la no confiscatoriedad. Comparar con Gorospe - Herrera (2007) 37.

124 Para algunos autores, es el sistema tributario como un conjunto (y no con cada figura tributaria en particular) el que debe responder al principio de capacidad económica, lo que así se traduce en el deber constitucional de contribuir [QUeralt y otros (2007) 127]; Fernández Segado considera que los principios materiales de justicia tributaria se proyectan sobre el conjunto del sistema tributario y no solo sobre todas y cada una de las diferentes figuras que lo integran. Calvo Ortega parece situarse en el otro extremo, al sostener que el principio de capacidad económica retrata una "situación subjetiva patrimonial en relación con obligaciones dinerarias determinadas", aunque se trataría de un planteamiento "puramente lógico: tiene capacidad económica el titular de una situación patrimonial concreta y suficiente frente a la obligación tributaria que se derive de esa misma situación", por lo que la capacidad económica se predica ante una obligación tributaria concreta. Este principio se extiende a todos los tributos -tasas, contribuciones especiales e impuestos- y a todas las personas, jurídicas o físicas [Calvo (2006) 52]. Para Gallego Peragón el principio de capacidad económica opera, sin ninguna reserva, frente al sistema tributario en su conjunto y no frente a cada figura impositiva particular, pues de otro modo se desvirtuaría el concepto constitucional de justicia tributaria [GALLEgo (2003) 118].

125 CASADO (1982) 219.

126 Palao (1976) 397.

127 Casado (1982) 197. Agrega que se está "ante unas demandas constitucionales que lo que exigen del Legislador no son ampulosas declaraciones de estilo, sino resultados aplicativos concretos y es, por tanto, en virtud de estos como corresponde controlar el cumplimiento del mandato constitucional" [CASADo (1982) 198]. La CE consagra principios y derechos materiales y no solo formales, por lo que el objeto de control no debe ser solo la ley sino también el resultado de aplicación de la ley. En su carácter de norma obligatoria, la Constitución 
la Administración, y por tanto, este principio exigiría, de parte de los órganos públicos, la persecución y control de la defraudación tributaria y la revisión de distorsiones que permiten que, por diferentes motivos, ciertos sectores escapen de la acción de los tributos o artificiosamente disminuyen su presión tributaria ${ }^{128}$.

También se ha discutido acerca de su aplicación en la imposición directa e indirecta ${ }^{129}$. El TCE parece sostener la idea de que los principios de justicia tributaria solo se proyectan con plenitud sobre las piezas básicas del sistema tributario y no sobre otros aspectos menos importantes (STCE 182/1997, FJ 70), especialmente sobre los impuestos directos (STC 296/1994) aunque, por cierto, cabe respecto de los demás tributos ${ }^{130}$.

Respecto de las tasas y las contribuciones especiales, si bien responden a principios de justicia conmutativa aun cabe espacio, aunque sea limitado, al principio de capacidad económica, lo que encuentra sustento en las leyes tributarias españolas, y así ha sido declarado en la STCE 296/1994131. En definitiva, el impacto de estos principios sobre esta clase de tributos ha sido sintetizado en los siguientes términos, expuestos por Gorospe Oviedo y Herrera Molina ${ }^{132}$ :

a) Principio de financiamiento preferentemente impositivo de los gastos realizados en relación con el conjunto de los ciudadanos.

b) En la medida que el importe de las tasas se separe del coste (costo) del servicio - del principio de equivalencia- la desviación queda plenamente sometida al principio de capacidad económica.

c) El principio de capacidad económica impondrá desviaciones del principio de equivalencia, cuando sea necesario para garantizar el mínimo exento personal y familiar o la prohibición de confiscatoriedad.

\section{4) CONCLUSIONES}

Dos reflexiones esenciales cabe efectuar.

Una valoración general debe dar cuenta del carácter sistemático de la elaboración dogmática española en materia de principios materiales de la

exige a la Administración y a los jueces ordinario y constitucional adecuar sus decisiones administrativas o judiciales a ella, mediante diferentes técnicas jurídicas acordes a cada una de esas instancias y conforme a las exigencias derivadas del control normativo y del control de resultados, dejando siempre a salvo el principio consagrado en la norma constitucional.

128 ESEVERri (2006) 39.

129 Si bien el principio de capacidad económica se predica para la generalidad del sistema tributario, se ha visto relativizado respecto de las tasas (SSTC 182/1997 y 296/1994; STS de 30 de noviembre de 2002).

130 Gorospe - Herrera (2007) 43.

131 Gorospe - Herrera (2007) 49.

132 Gorospe - Herrera (2007) 49. 
tributación. Esto implica tanto configurar cada institución como perfilarla y delimitarla ${ }^{133}$. Ello trae beneficios y costos. Un beneficio es la seguridad jurídica, la posibilidad de tener herramientas para crear leyes, dictar fallos, o evaluar a los anteriores. El costo se encuentra en las limitaciones, y los casos que no ven resueltos por dichas instituciones tan bien delimitadas.

De lo anterior es que resultan importantes los esfuerzos teóricos por defender la idea de una institución de cierre del sistema, como en el caso de España puede ser el principio de justicia tributaria, que disipa la dificultad que se presenta cuando los principios específicos de la tributación no logran dar solución de justicia a determinados casos.

Es posible darle un contenido cognoscible al principio de justicia tributaria. Requiere de esfuerzo analítico, de gran trabajo argumentativo, de la construcción de criterios plausibles y operacionalizables.

En segundo término, debe reflexionarse acerca de la coordinación normativa dentro del sistema jurídico tributario (que es parte del sistema jurídico general).

El juego de los principios materiales o de justicia tributaria, considerando al de capacidad económica como rector, puede ser sintetizado a través del siguiente modo ${ }^{134}$ : todos deben contribuir al sostenimiento de los gastos públicos en términos de igualdad, y la medida de la igualdad es la capacidad económica -que puede implicar la progresividad en el tributo-, la que a su vez presenta un límite mínimo -zona de inmunidad fiscal- cuál es el mínimo existencial y un límite máximo, constituido por la prohibición de confiscatoriedad.

Ese es el primer vínculo sistemático. Luego cabría integrar al resto de principios tributarios, esto es, los formales. Finalmente, de modo sistemático, a las demás reglas, principios y valores constitucionales (en particular, los que diferenciadamente concurren en cada caso).

Una interpretación sistemática conlleva a una coherencia del sistema, sin perder de vista que el objetivo de la norma constitucional es su realización. En cuanto tales, los principios de justicia tributaria deben encontrar su desenvolvimiento pleno en el sistema tributario, formado por un conjunto de normas legales y administrativas, referidas tanto a la estructura del tributo como a su aplicación concreta. Ello también supedita, no puede ser de otra forma, a las decisiones de los jueces y magistrados.

Por otro lado, las modulaciones, inflexiones o atenuaciones de estos principios (mas no su derogación), en casos concretos y delimitados, debe

133 Con esto me refiero a las ideas sustentadas mayoritariamente, pues las otras ideas, algunas de ellas muy bien fundadas, otorgan una geometría más variable a dichas instituciones.

134 Esto es abordado en Masbernat, Patricio (2010) "El principio de capacidad económica como principio jurídico material de la tributación: Su elaboración doctrinal en España". Revista Ius et Praxis, Año 16, No 1, 2010, pp. 303 - 332; y Gorospe - Herrera (2007). 
encontrar justificación plausible en otros fines constitucionales, con la necesaria ponderación ${ }^{135}$ de bienes jurídicos en juego ${ }^{136}$. Ello conduce a los espacios y posibilidades para los fines extrafiscales. También da lugar para fines como la lucha contra el fraude, en tutela del propio deber de contribuir. Las normas que se dicten a su respecto no pueden vulnerar precisamente las condiciones constitucionales impuestas al legislador para exigir ese deber de contribuir ${ }^{137}$.

\section{5) Bibliografía}

- Albiñana García-Quintana, César (1992) Sistema tributario español y comparado Madrid: Tecnos.

- Albiñana García-Quintana, César (1996). “El gasto público”. En Alzaga Villamil, Óscar (coordinador): Comentarios a la Constitución Española de 1978, Tomo III. Madrid: Cortes Generales-Editoriales de Derecho Reunidas. Disponible en Base de datos V LEX; Id. vLex: VLEX-331157. [Fecha de visita agosto de 2011].

- Aguilera Vásques, Mar (2005). "El reconocimiento del derecho de propiedad y los límites a su regulación”. En García Roca, Javier y Santolaya, Pablo (coordinadores): La Europa de los Derechos Humanos. El Convenio Europeo de Derechos Humanos. Madrid: Centro de Estudios Políticos y Constitucionales, pp. 767-800.

- Alarcón García, Gloria (2005). "Sistema fiscal y principios tributarios”. En Martín Dégano, Isidoro; Vaquera García, Antonio y Menéndez García, Gerardo (coordinadores): Estudios de derecho financiero y tributario en homenaje al profesor Calvo Ortega, Vol. 1. Madrid: Lex Nova, pp. 55-92.

135 Los conflictos normativos constitucionales se resuelven entre otras fórmulas, mediante el control de proporcionalidad (ponderación). De acuerdo a este, es posible restringir un derecho cuando deba tutelarse otro valor constitucionalmente relevante pero a condición de mantener la integridad del contenido esencial del derecho afectado. Ello será lícito si resulta idóneo para conseguir el objetivo perseguido; si resulta necesario (en cuanto no pueda lograrse el mismo resultado por otro medio menos gravoso para el afectado); y siempre que dicha restricción del derecho fundamental resulte proporcionada al fin (positivo) perseguido. Herrera (1997) 40.

136 Herrera (2010).

137 Entre ellas se encuentran las sentencias del TCE 45/1989 (de 20 de febrero, especialmente FJ 7o 7), 146/1994 (de 12 de mayo), 214/1994 (de 14 de julio), 194/2000 (de 19 de julio), 96/2002, 255/2004 (de 22 de diciembre). La doctrina ha destacado que en un grupo relevante de sentencias en que el TCE, reconociendo de modo implícito la existencia de un derecho fundamental a contribuir a los gastos públicos conforme a la capacidad económica, realiza una ponderación entre las necesidades de practicabilidad administrativa o la lucha contra el fraude, superando el genérico control de interdicción de la arbitrariedad. Herrera (2010); Gorospe - Herrera (2007) 43. 
- Albi Ibáñez, Emilio (1976). "Clásicos del enfoque de la capacidad de pago". Hacienda Pública Española, No 39, 1976, pp. 190-204.

- Alexy, Robert (2003). "Constitutional Rights, Balancing and Rationality”. Ratio Iuris, Vol. 16, N² 2, pp. 131-140.

- Alguacil Marí, María Pilar (1999), "Capacidad económica como parámetro de enjuiciamiento", Revista de Derecho Financiero y Hacienda Pública, No253. Madrid: Edersa.

- Álvarez Conde, Enrique (2008), Derecho Constitucional, Vol. I. Madrid: Tecnos.

- Atria Lemaitre, Fernando (1997). "Los peligros de la Constitución. La idea de igualdad en la jurisdicción nacional". Cuadernos de Análisis Jurídicos, No36. Santiago de Chile: Universidad Diego Portales.

- BARnes, J. (1994). "Introducción al principio de proporcionalidad en el Derecho Comparado y Comunitario". Revista de Administración Pública, CECP, No 135.

- Barranco Avilés, María del Carmen (2000) La teoría jurídica de los derechos fundamentales. Madrid: Dikynson.

- Bilbeny, Norbert (1991). "Igualdad y principio de solidaridad". En $A A V V$, El principio de igualdad en la Constitución Española: XI Jornadas de Estudio, Vol. 1. Madrid: Ministerio de Justicia, Centro de Publicaciones, pp. 49-58.

- Calvo Ortega, Rafael (2001). "Principio de igualdad tributaria". En Calvo Ortega, Rafael (director), Sección: Principio de igualdad tributaria, Anuario fiscal 2001 (septiembre 2002). Disponible en Base de datos V LEX [fecha de visita agosto de 2011].

- Calvo Ortega, Rafael (2006) Curso de Derecho Financiero, I. Derecho Tributario. Parte General, $10^{a}$ edición. Madrid: ThomsonCivitas.

- Calvo Ortega, Rafael (2011) Curso de Derecho Financiero, 15a Edición. Madrid: Editorial Civitas.

- Calvo Ortega, Rafael (2012) ¿Hay un principio de justicia tributaria? Pamplona: Cuadernos Civitas, Thomson Reuter/Editorial Aranzadi, 127 pp.

- Carrera Raya. Francisco José (1994) Manual de Derecho Financiero, Vol. I: Derecho Financiero y Teoría de los Ingresos Públicos. Madrid: Tecnos.

- Casado Ollero, Gabriel (1982). "El principio de capacidad y el control constitucional de la imposición indirecta (II). El contenido constitucional de la capacidad económica". Civitas, Revista Española de Derecho Financiero, No 34, pp. 185-236.

- Collado Yurrita, Miguel Ángel y Moreno González, Saturnina (2007). "Tema 2: Principios constitucionales del Derecho 
Tributario". En Collado Yurrita, Miguel Ángel (director) y Luchena Mozo, Gracia María (coordinador): Derecho Tributario, Parte General. 2a edición. Madrid: Editorial Atelier.

- Escribano López, Francisco (1991). "Principio de igualdad y deber de contribuir en la jurisprudencia constitucional". En VVAA, El principio de igualdad en la Constitución española: XI Jornadas de Estudio, Vol. 1. Madrid: Ministerio de Justicia, Centro de Publicaciones, pp. 713-776.

- Eseverri Martínez, Ernesto (2006) Derecho Tributario: Parte General. Valencia: Tirant lo Blanch.

- Falcón y Tella, Ramón (1995). "Exenciones y capacidad contributiva: la paradoja de la exención de los bienes necesarios para el desarrollo de actividades empresariales". Quincena Fiscal Aranzadi, No7/1995. Quincena Fiscal Aranzadi No 2/1999, Disponible en Base de Datos Westlaw Aranzadi, [fecha de visita agosto de 2011].

- Falcón y Tella, Ramón (1999). "El nuevo IRPF y la capacidad contributiva (II): coeficientes de corrección monetaria y rendimientos irregulares". Quincena Fiscal Aranzadi No 2/1999, Disponible en Base de Datos Westlaw Aranzadi, doc. BIB 1998\1313 [fecha de visita agosto de 2011].

- Falcón y Tella, Ramón (1999 A). "La posibilidad de gravar los hechos constitutivos de delito: SAP Madrid 24 enero 1998". Quincena Fiscal Aranzadi No11, Disponible en Base de Datos Westlaw Aranzadi, doc. BIB $1999 \backslash 711$ [fecha de visita agosto de 2011].

- FALCÓN Y TELLA, Ramón (1999 B). "Retroactividad de las normas tributarias y devengo del impuesto". Quincena Fiscal Aranzadi, No 21 (1996). Disponible en Base de Datos Westlaw Aranzadi, doc. BIB 1996\1312 [fecha de visita septiembre de 2011].

- Falcón y Tella, Ramón (2004). "El tipo único (flat tax) en el IRPF y la sorprendente propuesta de tipos progresivos en el IBI". Quincena Fiscal Aranzadi, No 20/2004. Disponible en Base de Datos Westlaw Aranzadi, doc. BIB $2004 \backslash 1757$ [fecha de visita agosto de 2011].

- Fernández Segado, Francisco (1997). "El diseño constitucional del deber de contribuir al sostenimiento de los gastos públicos". Revista Vasca de Administración Pública. Herri-Arduralaritzako Euskal Aldizkaria, No 47, 1, pp. 79-111.

- Gallego Peragón, José Manuel (2003). Los principios materiales de justicia tributaria. Comares, Granada.

- Gascó Casesnoves, María (1993). "Principios constitucionales y su aplicación al derecho tributario". Revista Palau, 14.

- Gorospe Oviedo, Juan Ignacio; Herrera Molina, Pedro Manuel (2007). "La virtualidad del principio de capacidad económica en el 
ordenamiento tributario español”. En Albiñana García-Quintana, César; González García, E.; Ramallo Massanet, Juan; Lejeune Valcárcel, Ernesto y Yábar Sterling, A. (coordinadores): Estudios en homenaje al profesor Pérez de Ayala. Madrid, Dykinson, pp. 29-56.

- Herrera Molina, Pedro Manuel (1997). "El principio de capacidad económica en Alemania y su relevancia para el derecho español". Noticias de la Unión Europea, No150, pp. 37-42.

- Herrera Molina, Pedro Manuel (1998) Capacidad económica y sistema fiscal. Madrid: Marcial Pons.

- Herrera Molina, Pedro Manuel (2010). "El Principio de Capacidad Económica". Disponible en Base de Datos de Conocimientos Jurídicos IUSTEL [fecha de visita julio de 2011].

- Herrera Molina, Pedro Manuel (1996). "Una decisión audaz del Tribunal Constitucional alemán: el conjunto de la carga tributaria del contribuyente no puede superar el 50 por 100 de sus ingresos". Impuestos, $\mathrm{N}^{\circ} 14$, pp. 1033-1049.

- Kirchnof, Paul (1990). "La influencia de la Constitución Alemana en su legislación tributaria". Disponible en Base de datos Tirant OnLine, TOL314.020 (Owww.tirantonline.com [fecha de visita julio de 2011]

- López Guerra, Luis, y otros (2007) Derecho Constitucional, Volumen I: El ordenamiento constitucional. Derechos y deberes de los ciudadanos. Valencia: Tirant lo Blach.

- Masbernat, Patricio (2010). "El principio de capacidad económica como principio jurídico material de la tributación: Su elaboración doctrinal en España". Revista Ius et Praxis, Año 16, No 1, pp. 303 332.

- Masbernat, Patricio (2012). "Un análisis crítico de la doctrina relativa a los principios materiales de la tributación en Chile". En AAVV, Problemas Actuales de Derecho Tributario comparado. Una perspectiva de Iberoamérica. Santiago de Chile: Librotecnia, pp. 433-474.

- Medina Guerrero, Manuel (2010). "Las Obligaciones Tributarias". Derecho Constitucional III. Disponible en Base de datos IUSTEL [fecha de visita septiembre de 2011].

- Mongay I Soler, M. (1995). "Aplicabilidad del principio de capacidad económica como fuente material del Derecho en la jurisprudencia”. Revista Española de Derecho Financiero, No 87. Madrid: Editorial Civitas.

- Palao Taboada, Carlos (1976). "Apogeo y crisis del principio de capacidad contributiva". Estudios jurídicos en homenaje al profesor Federico de Castro, Vol. II, pp. 377 y ss. 
- Palao Taboada, Carlos (1995). "Los principios de capacidad económica e igualdad en la jurisprudencia del Tribunal Constitucional español". Civitas, Revista Española de Derecho Financiero, $\mathrm{N}^{\circ}$ 88. Madrid: Editorial Civitas, pp. 629-642.

- Palao Taboada, Carlos (2005). "Nueva visita al principio de capacidad contributiva". Civitas. Revista española de derecho financiero, No 124. Madrid: Editorial Civitas, pp. 767-783

- Pérez de Ayala Becerril, Miguel y Pérez de Ayala, José luis (2008). "Fuentes y principios del derecho tributario". Fundamentos de Derecho tributario, Base de Datos VLEX, Id. vLex: VLEX39673370. Disponible en http://www.vlex.com/vid/39673370, [fecha de visita julio 2012].

- Pérez Luño, Antonio (2004) Los derechos fundamentales, 8a edición. Madrid: Tecnos.

- Prada Fernández de Sanmamed, José Luis (2009). "Los principios rectores de la política social y económica". En Derecho Constitucional III. Disponible en Base de datos IUSTEL [fecha de visita septiembre de 2011].

- Queralt, Martín; Lozano, Carmelo; Tejerizo, José y Casado, Gabriel (2007) Curso de Derecho Financiero y Tributario, $18^{a}$ edición. Madrid: Tecnos.

- Rodríguez Bereijo, Álvaro (1998). "Los principios de la imposición en la jurisprudencia constitucional española". Civitas Revista Española de Derecho Financiero, No 100, pp. 593-626.

- Rodríguez Bereijo, Álvaro (1998). "Jurisprudencia constitucional y principios de la imposición". Disponible en Base de datos Tirant On Line, documento TOL314.024 Owww.tirantonline.com [fecha de visita agosto de 2011].

- Romero García, Felipe (2005) El valor sistema tributario: acerca de su integración entre los principios de la imposición. Cádiz: Servicio de Publicaciones de la Universidad de Cádiz.

- Tipke, Klaus (1990) Principios constitucionales en el derecho tributario alemán, Seminario Hispano Alemán de Derecho Tributario. Madrid: IEF, Edición sin encuadernar. 